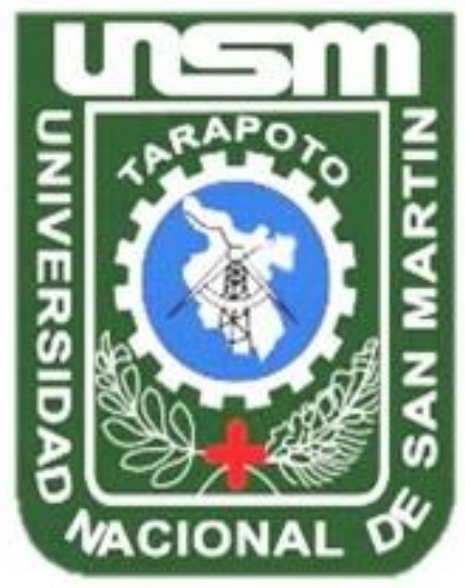

\title{
@(1) (1)
}

Esta obra está bajo una Licencia

Creative Commons Atribución-

NoComercial-Compartirigual 2.5 Perú.

Vea una copia de esta licencia en

http://creativecommons.org/licenses/by-nc-sa/2.5/pe/ 


\section{UNIVERSIDAD NACIONAL DE SAN MARTÍN- TARAPOTO}

FACULTAD DE CIENCIAS ECONÓMICAS

ESCUELA PROFESIONAL DE TURISMO

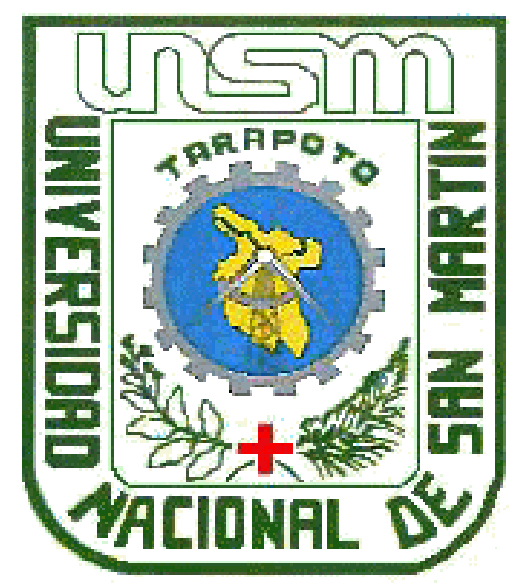

Promoción en redes sociales y participación en el mercado de la Asociación Peruana de Agencias de Viajes y Turismo San Martín - APAVIT, en el distrito de Tarapoto, 2017

Tesis para optar el Título Profesional de Administración en Turismo

AUTORES:

Mayra Meliza Aching Rios

Gabriela Torres Ruiz

ASESOR:

Lic. Tur. Mtro. Jessica Del Pilar Cabel Rabines

Tarapoto - Perú 


\section{UNIVERSIDAD NACIONAL DE SAN MARTÍN - TARAPOTO}

FACULTAD DE CIENCIAS ECONÓMICAS

ESCUELA PROFESIONAL DE TURISMO

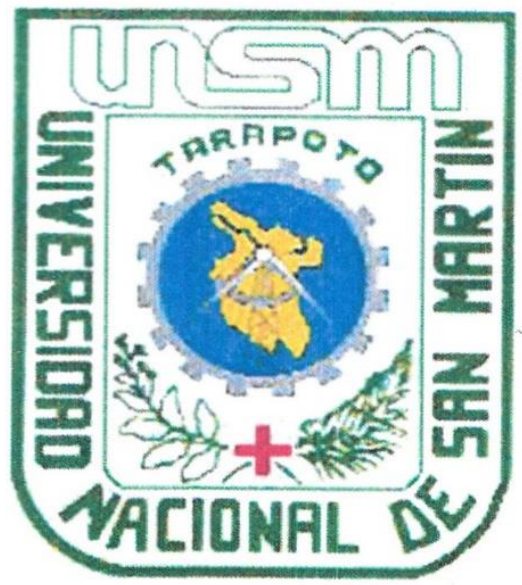

Promoción en redes sociales y participación en el mercado de la Asociación Peruana de Agencias de Viajes y Turismo San Martín - APAVIT, en el distrito de Tarapoto, 2017.

\section{AUTORES:}

Mayra Meliza Aching Rios

Gabriela Torres Ruiz

Sustentada y aprobada el 17 de abril del 2019, por los siguientes jurados:

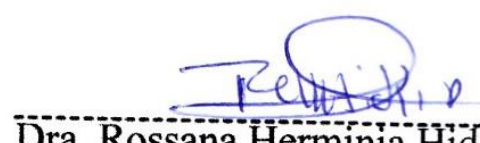

D̀ra. Rossana Herminia Hidăgo Pōżì Presidente

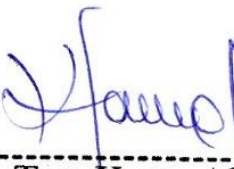

Lic. Ädm. Tur. Katty Äilamo Larrañaga Vocal

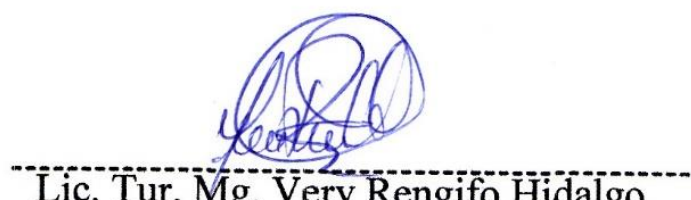

Lic. Tur. Mg. Very Rengifo Hidälgo Secretaria

Lic.Tur. Mtro.Jessicat PelPilar Cabel Rabines Asesor 


\section{Declaratoria de Autenticidad}

Mayra Meliza Aching Rios, identificada con DNI N ${ }^{\circ} 70883427$ y Gabriela Torres Ruiz, identificada con DNI $N^{\circ}$ 48204063, egresadas de la Facultad de Ciencias Económicas, Escuela Profesional de Turismo, de la Universidad Nacional de Nacional de San Martin Tarapoto, con la tesis titulada: PROMOCIÓN EN REDES SOCIALES Y PARTICIPACIÓN EN EL MERCADO DE LA ASOCIACIÓN PERUANA DE AGENCIAS DE VIAJES Y TURISMO SAN MARTÍN - APAVIT, EN EL DISTRITO DE TARAPOTO, 2017.

Declaramos bajo juramento que:

1. La tesis presentada es de nuestra autoría.

2. Hemos respetado las normas internacionales de citas y referencias para las fuentes consultadas. Por tanto, la tesis no ha sido plagiada ni total ni parcialmente.

3. La tesis no ha sido auto plagiado; es decir, no ha sido publicada ni presentada anteriormente para obtener algún grado académico previo o título profesional.

4. Los datos presentados en los resultados son reales, no han sido falseados, ni duplicados, ni copiados y por tanto los resultados que se presenten en la tesis se constituirán en aportes a la realidad investigada.

De considerar que el trabajo cuenta con una falta grave, como el hecho de contar con datos fraudulentos, demostrar indicios y plagio (al no citar la información con sus autores), plagio (al presentar información de otros trabajos como propios), falsificación (al presentar la información e ideas de otras personas de forma falsa), entre otros, asumo las consecuencias y sanciones que de mi acción se deriven, sometiéndome a la normatividad vigente de la Universidad Nacional de San Martín - Tarapoto.

Tarapoto, 29 de abril del 2019
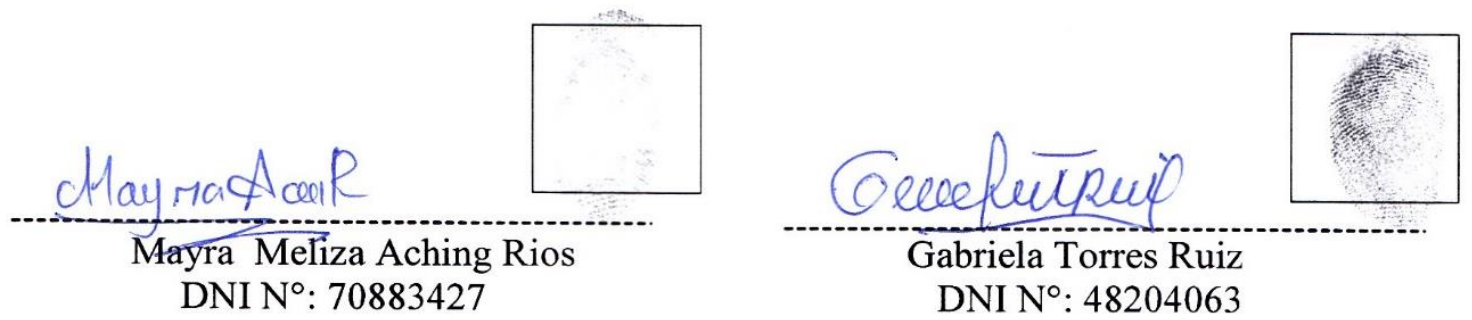
Formato de autorización NO EXCLUSIVA para la publicación de trabajos de investigación, conducentes a optar grados académicos y títulos profesionales en el Repositorio Digital de Tesis.

1. Datos del autor:

\begin{tabular}{|ll|}
\hline Apellidos yombres: Acling Rios Mayra Meliza \\
\hline Código de alumno: 70883427 & Teléfono: 989674588 \\
\hline Correo electrónico : aching. meliza@gmail.com & DNI: 70883427 \\
\hline
\end{tabular}

(En caso haya más autores, llenar un formulario por autor)

2. Datos Académicos

\begin{tabular}{|l|}
\hline Facultad de: Ciencias Económicas \\
\hline Escuela Profesional de: Turismo \\
\hline
\end{tabular}

3. Tipo de trabajo de investigación

\begin{tabular}{|llll|}
\hline Tesis & $(\times)$ & Trabajo de investigación & $(\quad)$ \\
\hline Trabajo de suficiencia profesional & $(\quad)$ & & \\
\hline
\end{tabular}

4. Datos del Trabajo de investigación

Titulo: Promoción en redes sociales y participación en el mercado de la Asociación Pervana de Agencias de viajes Tunismo San Martín-APAVIT, en el distrito de Tarapoto, 2017.

Año de publicación: 2019

5. Tipo de Acceso al documento

\begin{tabular}{|lcc|}
\hline Acceso público & $(x)$ Embargo & $($ ) \\
\hline Acceso restringido ** & $(\quad)$ & \\
\hline
\end{tabular}

Si el autor elige el tipo de acceso abierto o público, otorga a la Universidad Nacional de San Martín - Tarapoto, una licencia No Exclusiva, para publicar, conservar y sin modificar su contenido, pueda convertirla a cualquier formato de fichero, medio o soporte, siempre con fines de seguridad, preservación y difusión en el Repositorio de Tesis Digital. Respetando siempre los Derechos de Autor y Propiedad Intelectual de acuerdo y en el Marco de la Ley 822.

En caso que el autor elija la segunda opción, es necesario y obligatorio que indique el sustento correspondiente:

6. Originalidad del archivo digital.

Por el presente dejo constancia que el archivo digital que entrego a la Universidad Nacional de San Martín - Tarapoto, como parte del proceso conducente a obtener el título profesional o grado académico, es la versión final del trabajo de investigación sustentado y aprobado por el Jurado. 


\section{Otorgamiento de una licencia CREATIVE COMMONS}

Para investigaciones que son de acceso abierto se les otorgó una licencia Creative Commons, con la finalidad de que cualquier usuario pueda acceder a la obra, bajo los términos que dicha licencia implica

\section{https://creativecommons.org/licenses/by-nc-sa/2.5/pe/}

El autor, por medio de este documento, autoriza a la Universidad Nacional de San Martín - Tarapoto, publicar su trabajo de investigación en formato digital en el Repositorio Digital de Tesis, al cual se podrá acceder, preservar y difundir de forma libre y gratuita, de manera íntegra a todo el documento.

Según el inciso 12.2, del artículo $12^{\circ}$ del Reglamento del Registro Nacional de Trabajos de Investigación para optar grados académicos y títulos profesionales - RENATI "Las universidades, instituciones y escuelas de educación superior tienen como obligación registrar todos los trabajos de investigación y proyectos, incluyendo los metadatos en sus repositorios institucionales precisando si son de acceso abierto o restringido, los cuales serán posteriormente recolectados por el Repositorio Digital RENATI, a través del Repositorio ALICIA".

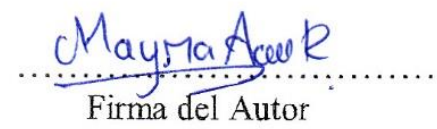

8. Para ser llenado en la Oficina de Repositorio Digital de Ciencia y Tecnología de Acceso Abierto de la UNSM - T.

Fecha de recepción del documento:

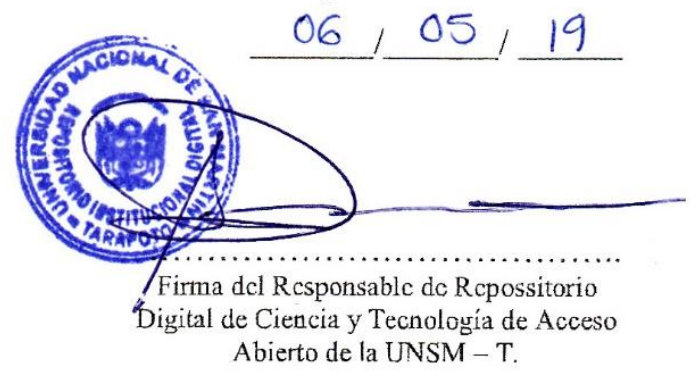

\footnotetext{
*Acceso abierto: uso lícito que confiere un titular de derechos de propiedad intelectual a cualquier persona, para que pueda acceder de manera inmediata y gratuita a una obra, datos procesados o estadísticas de monitoreo, sin necesidad de registro, suscripción, ni pago, estando autorizada a leerla, descargarla, reproducirla, distribuirla, imprimirla, buscarla y enlazar textos completos (Reglamento de la Ley No 30035).

** Acceso restringido: el documento no se visualizará en el Repositorio.
} 
Formato de autorización NO EXCLUSIVA para la publicación de trabajos de investigación, conducentes a optar grados académicos y títulos profesionales en el Repositorio Digital de Tesis.

1. Datos del autor:

\begin{tabular}{|l|l|}
\hline Apellidos y nombres: Torres Ruiz Gabriela \\
\hline Código de alumno : 48204063 & Teléfono: $910^{2} 46228$ \\
\hline Correo electrónico : gabrielatorresrui3930gmail.com DNI: 48204063
\end{tabular}

(En caso haya más autores, llenar un formulario por autor)

2. Datos Académicos

\begin{tabular}{|l|}
\hline Facultad de: Ciencias Económicas \\
\hline Escuela Profesional de: Turismo \\
\end{tabular}

3. Tipo de trabajo de investigación

\begin{tabular}{|llll|}
\hline Tesis & $(\searrow)$ & Trabajo de investigación & $(\quad)$ \\
\hline Trabajo de suficiencia profesional & $(\quad)$ & & \\
\hline
\end{tabular}

4. Datos del Trabajo de investigación

Titulo: Promóción en redes Sociales y Participación en el
mercado de la Asociación Peruana de Agencias de Viajes 4
Turismo San Martín - APAvIT, en el distritu de Tarapoto. 2017.
Año de publicación: 2019

5. Tipo de Acceso al documento

\begin{tabular}{|lll|}
\hline Acceso público * & $(\searrow)$ Embargo & $(\quad)$ \\
\hline Acceso restringido ** & $(\quad)$ & \\
\hline
\end{tabular}

Si el autor elige el tipo de acceso abierto o público, otorga a la Universidad Nacional de San Martín - Tarapoto, una licencia No Exclusiva, para publicar, conservar y sin modificar su contenido, pueda convertirla a cualquier formato de fichero, medio o soporte, siempre con fines de seguridad, preservación y difusión en el Repositorio de Tesis Digital. Respetando siempre los Derechos de Autor y Propiedad Intelectual de acuerdo y en el Marco de la Ley 822.

En caso que el autor elija la segunda opción, es necesario y obligatorio que indique el sustento correspondiente:

6. Originalidad del archivo digital.

Por el presente dejo constancia que el archivo digital que entrego a la Universidad Nacional de San Martín - Tarapoto, como parte del proceso conducente a obtener el título profesional o grado académico, es la versión final del trabajo de investigación sustentado y aprobado por el Jurado. 


\section{Otorgamiento de una licencia CREATIVE COMMONS}

Para investigaciones que son de acceso abierto se les otorgó una licencia Creative Commons, con la finalidad de que cualquier usuario pueda acceder a la obra, bajo los términos que dicha licencia implica

\section{https://creativecommons.org/licenses/by-nc-sa/2.5/pe/}

El autor, por medio de este documento, autoriza a la Universidad Nacional de San Martin - Tarapoto, publicar su trabajo de investigación en formato digital en el Repositorio Digital de Tesis, al cual se podrá acceder, preservar y difundir de forma libre y gratuita, de manera íntegra a todo el documento.

Según el inciso 12.2, del artículo $12^{\circ}$ del Reglamento del Registro Nacional de Trabajos de Investigación para optar grados académicos y títulos profesionales - RENATI "Las universidades, instituciones y escuelas de educación superior tienen como obligación registrar todos los trabajos de investigación y proyectos, incluyendo los metadatos en sus repositorios institucionales precisando si son de acceso abierto o restringido, los cuales serán posteriormente recolectados por el Repositorio Digital RENATI, a través del Repositorio ALICIA".

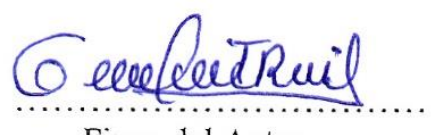

Firma del Autor

8. Para ser llenado en la Oficina de Repositorio Digital de Ciencia y Tecnología de Acceso Abierto de la UNSM - T.

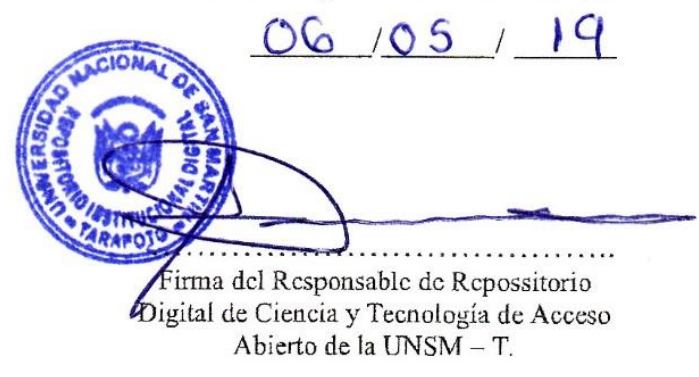

\footnotetext{
*Acceso abierto: uso lícito que confiere un titular de derechos de propiedad intelectual a cualquier persona, para que pueda acceder de manera inmediata y gratuita a una obra, datos procesados o estadísticas de monitoreo, sin necesidad de registro, suscripción, ni pago, estando autorizada a leerla, descargarla, reproducirla, distribuirla, imprimirla, buscarla y enlazar textos completos (Reglamento de la Ley No 30035).

** Acceso restringido: el documento no se visualizará en el Repositorio.
} 


\section{Dedicatoria}

A mis padres, por su gran amor y apoyo incondicional siempre durante el desarrollo de toda mi carrera profesional. A mi novio, quien, con su amor y paciencia, me apoyo y alentó para continuar hasta el final de mi carrera profesional.

Mayra Meliza Aching Rios

A mi madre por ser el pilar más importante en mi formación profesional, por su ejemplo de perseverancia para lograr las metas en la vida. A mi padre por su cariño y apoyo incondicional. Mi familia, que son mi inspiración para seguir adelante.

Gabriela Torres Ruiz 


\section{Agradecimiento}

A Dios, por darnos la vida y todas sus Bendiciones, a los docentes de la escuela Profesional de Administración en Turismo de la Universidad Nacional de San Martín, especialmente a nuestra asesora de investigación por su paciencia y tiempo en nuestra investigación, a los representantes de la Asociación Peruana de Agencias de Viajes y Turismo San Martín APAVIT, por facilitar importante información requerida con respecto al trabajo de investigación mediante la encuesta realizada, a los asociados activos en APAVIT por colaborar con los instrumentos de recolección de datos y, por apoyarnos con información valiosa para la investigación.

Mayra Meliza Aching Rios y

Gabriela Torres Ruiz 


\section{Índice general}

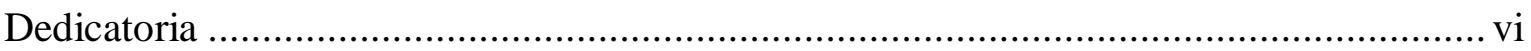

Agradecimiento............................................................... vii

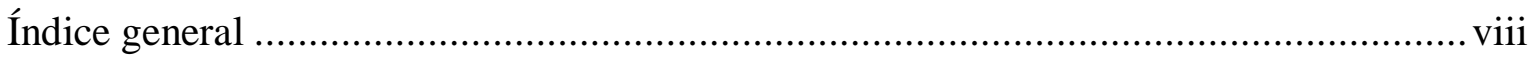

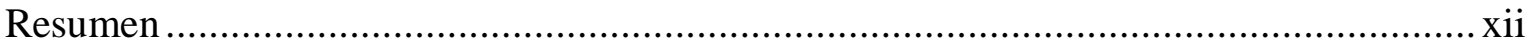

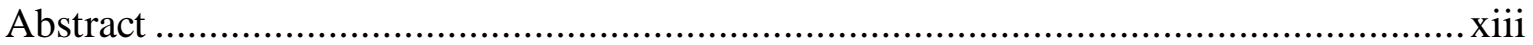

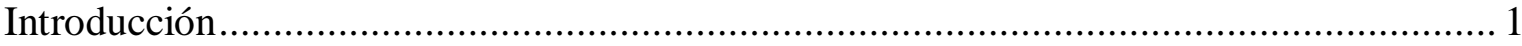

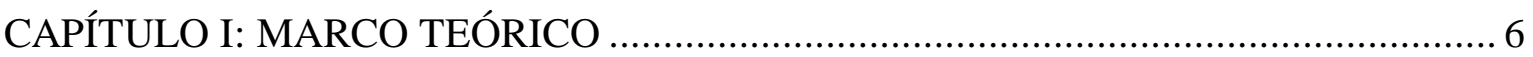

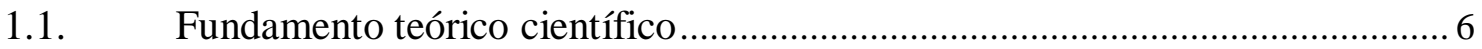

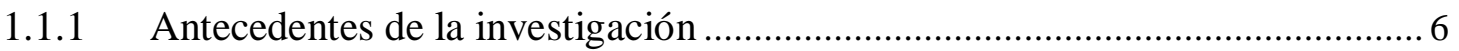

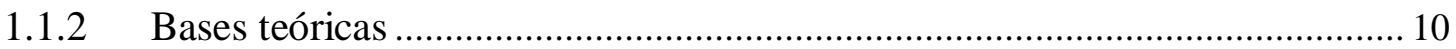

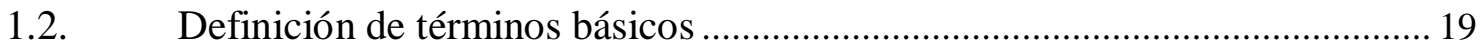

CAPÍTULO II: MATERIALES Y MÉTODOS ......................................................... 20

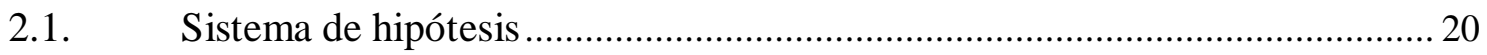

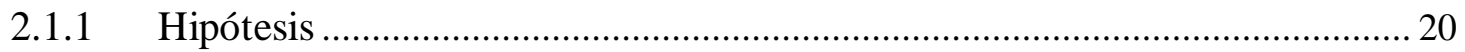

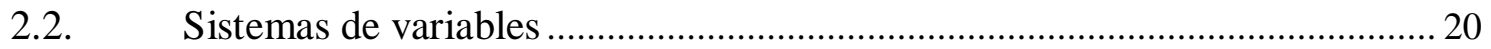

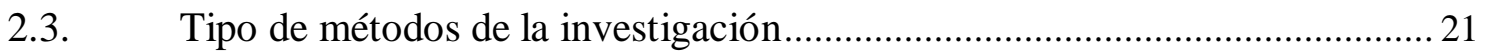

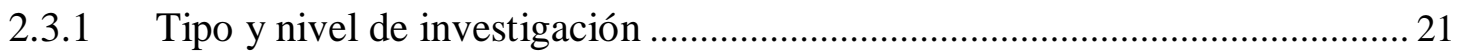

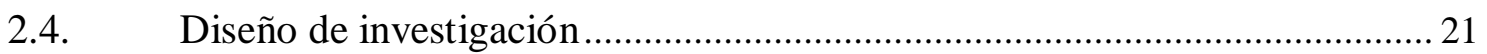

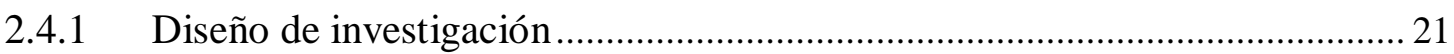

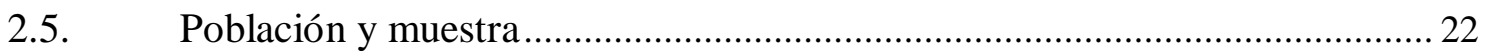

CAPÍTULO III: RESULTADOS DE LA INVESTIGACIÓN ....................................... 23

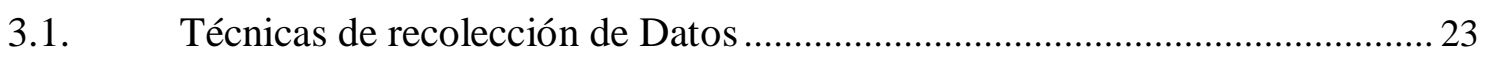

3.1.1. Técnicas de procesamiento y análisis de datos ......................................... 24

3.2. Tratamiento estadístico e interpretación de cuadros........................................... 25

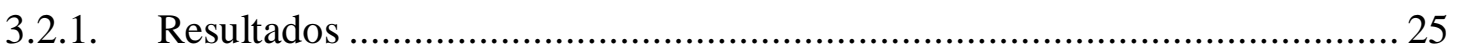

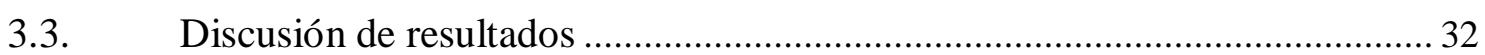

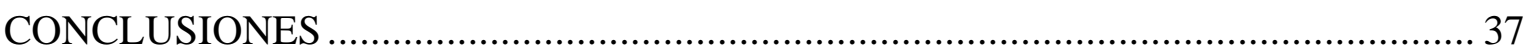

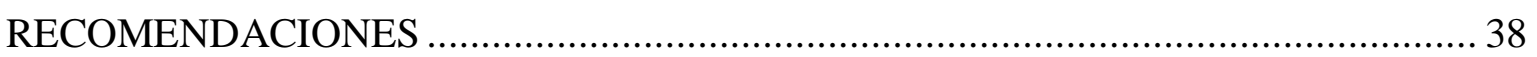

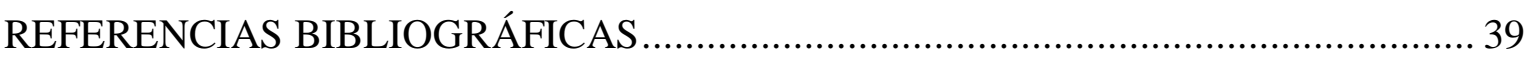

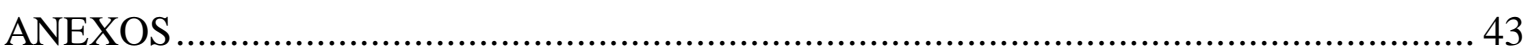




\section{Índice de tablas}

Tabla 1. Medidas Estadísticas descriptivas sobre la promoción de redes sociales y participación en el mercado - 2017 .

Tabla 2. Nivel de promoción de las Redes Sociales - 2017 25

Tabla 3. Nivel de participación en el Mercado, 2017 26

Tabla 4. Pruebas de normalidad sobre las puntuaciones de las variables de estudio..... 28

Tabla 5. Correlaciones entre variables y prueba de hipótesis de la promoción en redes sociales y participación del mercado de las agencias de viajes asociadas a APAVIT San Martín - 2017. 


\section{Índice de figuras}

Figura 1. Promoción en redes sociales de las agencias asociadas a APAVIT San Martín, 2017 26

Figura 2. Participación en el mercado de las agencias asociadas a APAVIT San Martín, 2017 27

Figura 3. Frecuencia de variables. 28

Figura 4. Relación entre la promoción en redes sociales y participación en el mercado de las agencias de viajes asociadas a APAVIT San Martín, 2017. 30

Figura 5. Relación entre la oferta y promoción en redes sociales, 2017 30

Figura 6. Relación entre la demanda y promoción en redes sociales, 2017. 31

Figura 7. Relación entre la competencia y promoción en redes sociales, 2017 32 


\section{Lista de siglas y abreviaturas}

PRS : $\quad$ Promoción de redes sociales.

PM : $\quad$ Participación en el mercado.

F : $\quad$ Facebook.

PW : $\quad$ Página web.

FP $\quad: \quad$ Fanpage.

PM : $\quad$ Publicación en el muro.

PBV : $\quad$ Página de bienvenida con video.

APAVIT: $\quad$ Asociación Peruana de Agencias de Viajes y Turismo en la Región San Martín. 


\section{Resumen}

La investigación titulada "Promoción en Redes Sociales y Participación en el Mercado de la Asociación Peruana de Agencias de Viajes y Turismo San Martín - APAVIT, en el distrito de Tarapoto, 2017”, aborda el problema para ver cómo se relaciona la promoción en redes sociales y la participación en el mercado con el objetivo de determinar la correlación entre ambas variables. La investigación es de tipo no experimental referido a las ciencias sociales, con un diseño descriptivo correlacional y una muestra de 16 agencias de viajes asociadas y activas a APAVIT San Martín. Como resultados encontramos que 62\% de agencias que consideran que la promoción en redes sociales es media, un $25 \%$ que lo considera como alta y un $13 \%$ bajo, y se obtuvo un grado de correlación muy baja y con dirección positiva de 0,571 entre dichas variables. Se llegó a la conclusión que las variables se relacionan directamente; es decir, la promoción en redes sociales de las agencias de viaje asociadas a APAVIT San Martín, con sus dimensiones de Facebook, página web y Fanpage, inciden directamente en la participación en el mercado en sus dimensiones de oferta, demanda y competencia de las agencias de viajes.

Palabras clave: Promoción en redes sociales, participación en el mercado, agencias de viaje, APAVIT. 


\begin{abstract}
The following research titled as "Promotion in Social Networks and Market Participation of the Peruvian Association of Travel Agencies and Tourism San Martin - APAVIT, in the district of Tarapoto, 2017", addressing the problem to see how it relates to the promotion in networks social and market participation with the aim of establishing the correlation between both variables. The research is a non-experimental type referred to the social sciences, with a descriptive correlational design and a sample of 16 travel agencies associated and active to APAVIT San Martin. As results we found that $62 \%$ of the agencies that consider the promotion is a social network in the media, $25 \%$ consider it as a high and low $13 \%$ low, and get a very low degree of correlation and a positive of 0.571 between said variables. It was concluded that the variables are directly related; that is to say, the promotion in social networks of the travel agencies to APAVIT San Martin, with its dimensions of Facebook, website and Fan page, directly affect the participation in the market in its dimensions of supply, demand and competition of the agencies Travel.
\end{abstract}

Keywords: Promotion in social networks, participation in the market, travel agencies, APAVIT 


\section{Introducción}

La presente investigación titulada "Promoción en Redes Sociales y Participación en el Mercado de la Asociación Peruana de Agencias de Viajes y Turismo San Martín APAVIT, en el distrito de Tarapoto, 2017”, es de suma importancia, ya que la promoción en redes sociales es relevante en la participación del mercado en la industria del sector turístico, específicamente en las agencias de viajes.

En la provincia de San Martín, específicamente en el distrito de Tarapoto, existen muchas agencias de viajes que brindan distintos servicios turísticos en paquetes, esto gracias a la gran cantidad de lugares turísticos que alberga la región. Esto ha permitido a las agencias de viaje adoptar estrategias para promocionar sus servicios mediante redes sociales más usadas como: Facebook, páginas web y Fanpage. Esto permite incrementar la participación en el mercado de éstas empresas en lo que se refiere a oferta, demanda y competencia. Sin embargo, a pesar de pertenecer a una asociación de alto prestigio como es la Asociación Peruana de Agencias de Viajes y Turismo en la Región San Martín - APAVIT, éstas no logran tener una buena promoción en redes sociales de los servicios que ofrecen, esto se observa en las pocos clientes que captan debido a las escasas herramientas de promoción con las que cuentan sin preocuparse en mejorar y variar los servicios que ofrecen, limitando así una buena participación en el mercado y el bajo desarrollo de éstas.

El propósito de la investigación es determinar el grado de relación entre la promoción en redes sociales y participación en el mercado de la Asociación Peruana de Agencias de Viajes y Turismo San Martín - APAVIT en el distrito de Tarapoto, dichos datos precisos serán tomados para posteriores investigaciones con respecto a la promoción en redes sociales y participación en el mercado de las empresas mencionadas. La investigación es descriptiva correlacional no experimental, se utilizará como muestra a 16 agencias de viaje en el distrito de Tarapoto asociadas a APAVIT y, como técnica se utilizó las encuestas.

Además consta de cinco capítulos estructurados de la siguiente manera: I. Marco teórico, se mencionan los antecedentes, teorías relacionadas al tema. II. Materiales y métodos, donde hace Hipótesis, variables, la metodología, muestra, técnicas e instrumentos utilizados en la investigación. III. Resultados de la investigación, hace referencia a los resultados de la investigación de forma descriptiva y correlacional, y la discusión de resultados. Además tenemos las Conclusiones, recomendaciones, bibliografía y anexos, todos estos están detallados de forma armoniosa respetando las normas APPA y las fuentes respectivas. 


\section{Planteamiento del problema}

El turismo en los últimos años a nivel mundial, es considerado como una categoría importante dentro del comercio internacional de servicios, lo cual ha significado un pilar importante en el crecimiento de la economía de forma ininterrumpida. Su crecimiento se debe a la continua expansión y servicios diversificados que se ofrecen, y representa el 7\% de las exportaciones mundiales generando en el 2016 ingresos 1, 220, 000 millones de dólares (Organización Mundial del Turismo [OMT], 2018). Entre las empresas que han formado parte de del dinamismo económico generado por el turismo, son las agencias de viajes, brindando paquetes con diferentes servicios a precios accesibles del turista.

En el Perú, el turismo ha crecido notoriamente con un 7,7\% en el 2016 (Cámara Nacional del Turismo en el Perú [CANATUR], 2018). Esto ha significado un crecimiento en las empresas que forman parte de la industria hotelera como son las agencias de viajes. Estas brindan una gran cantidad de servicios operando bajo reglas y normas peruanas para brindar seguridad al Turista. Sin embargo, son pocas las que cumplen los requisitos y están asociadas a un gremio.

La región San Martín ha crecido en relación al número de turistas en el 2018 con un 92,7\% de pernoctaciones, ello se debe a que cuenta con una gran cantidad de atractivos turísticos que alberga nuestra región (Peñaranda, 2018). Estos índices han derivado a un crecimiento de las agencias de viajes que en una pequeña minoría están formalizadas y asociadas. Éstas generalmente carecen de estrategias para promocionar los servicios que ofrecen y tener una mayor participación en el mercado generando mayores utilidades a las empresas.

Según Reales, Bohórquez y Rueda (1993), las redes sociales son la forma en que conceptualizamos a un sistema humano abierto, cooperativo y de propósito constructivo que, mediante un intercambio dinámico, ya sea de energía, materia e información de sus integrantes logra la potenciación de sus recursos (Citado en Carrión, 2015 p. 51). Dentro de las cuales las más utilizadas son el Facebook, páginas web y Fanpage. Con respecto a la participación en el mercado, se refiere al porcentaje que una empresa tiene del mercado, expresado en unidades del mismo tipo o el volumen de ventas explicado en valores monetarios de un producto o servicio específico (Palomino, 2016).

La promoción en redes sociales se ha convertido en una herramienta fundamental e indispensable para que éstas tengan una mayor participación en el mercado mediante la oferta, demanda y competencia. Asimismo, la Asociación Española de la Economía (AEP), 
dio a conocer que el $85 \%$ de compañías determinan el uso de las redes sociales con fines de negocio, lo que inducen a través de ello incrementan el nivel de promoción en cuanto a los productos y servicios que esta brinda a sus clientes (Revista RRHH Digital, 2017).

En el distrito de Tarapoto tenemos una asociación Peruana de Agencias de Viajes APAVIT, conformada por 23 agencias de viajes asociadas, de las cuales sólo 16 están activas (Asociación Peruana de Agencias de Viajes y Turismo en la Región San Martín, 2018). Éstas brindan paquetes turísticos a los diferentes lugares turísticos locales. Sin embargo, a pesar de pertenecer a una asociación de alto prestigio, éstas no logran tener una buena promoción en redes sociales de los servicios que ofrecen, esto se observa en las pocos clientes que captan y a las escasas herramientas de promoción con las que cuentan, limitando así una buena participación en el mercado y el bajo desarrollo de éstas.

\section{Formulación del problema}

\section{Problema general}

¿Cómo se relaciona la promoción en redes sociales y participación en el mercado de la Asociación Peruana de Agencias de Viajes y Turismo San Martín - APAVIT, en el distrito de Tarapoto, 2017 ?

\section{Problemas específicos}

¿Cómo se relaciona la promoción en redes sociales con la oferta inherente a la participación en el mercado de la Asociación Peruana de Agencias de Viajes y Turismo San Martín APAVIT, en el distrito de Tarapoto, 2017?

¿Cómo se relaciona la promoción en redes sociales con la demanda inherente a la participación en el mercado de la Asociación Peruana de Agencias de Viajes y Turismo San Martín - APAVIT, en el distrito de Tarapoto, 2017 ?

¿Cómo se relaciona la promoción en redes sociales con la competencia inherente a la participación en el mercado de la Asociación Peruana de Agencias de Viajes y Turismo San Martín - APAVIT, en el distrito de Tarapoto, 2017 ?

\section{Objetivos}

\section{General}

Determinar el grado de relación entre la promoción en redes sociales y participación en el mercado de la Asociación Peruana de Agencias de Viajes y Turismo San Martín - APAVIT, en el distrito de Tarapoto, 2017. 


\section{Específicos}

Conocer el grado de relación entre la promoción en redes sociales con la oferta inherente a la participación en el mercado de la Asociación Peruana de Agencias de Viajes y Turismo San Martín - APAVIT, en el distrito de Tarapoto, 2017.

Conocer el grado de relación entre la promoción en redes sociales con la demanda inherente a la participación en el mercado de la Asociación Peruana de Agencias de Viajes y Turismo San Martín - APAVIT, en el distrito de Tarapoto, 2017.

Conocer el grado de relación entre la promoción en redes sociales y con la competencia inherente a la participación en el mercado de la Asociación Peruana de Agencias de Viajes y Turismo San Martín - APAVIT, en el distrito de Tarapoto, 2017.

\section{Justificación}

\section{Justificación por conveniencia}

Se justifica a la obtención de datos reales de correlación de la promoción en redes sociales y participación en el mercado de la Asociación Peruana de Agencias de Viajes y Turismo San Martín - APAVIT, en el distrito de Tarapoto, para contribuir al conocimiento de empresarios y autoridades pertinentes. Además, se justifica el presente estudio de investigación, por significar la consolidación de la formación profesional y la importancia que tiene la tesis para obtener el título de Administración en Turismo en la Universidad Nacional de San Martín.

\section{Justificación social}

Socialmente se justifica, ya que la Región San Martín cuenta con mucha diversidad de recursos turísticos que aporta al dinamismo económico y social. Y en consecuencia debido a la demanda turística existe una significativa cantidad agencias de viajes que generan empleo a muchas familias y jóvenes en la región.

\section{Justificación práctica}

El presente estudio se realiza porque existe la necesidad de mejorar la promoción en redes sociales y la participación en el mercado de las agencias de viajes en el distrito de Tarapoto. En consecuencia, la obtención de resultados serán considerados y tomados por las autoridades y empresarios de este sector con fines de competencia generando así mayor rentabilidad de estas empresas y un mayor dinamismo económico en la región. 


\section{Justificación Teórica:}

Se realiza con el propósito de aportar conocimiento a la comunidad científica sobre la promoción en redes sociales y la participación en el mercado con sus respectivas dimensiones de cada una de las variables mencionadas, cuyos resultados serán tomados para elaborar distintos estudios similares usando las teorías mencionadas a lo largo del estudio. 


\section{CAPÍTULO I \\ MARCO TEÓRICO}

\subsection{Fundamento teórico científico}

\subsubsection{Antecedentes de la investigación}

\section{Internacionales}

Alcívar y Cantos, (2014), en su trabajo de investigación de tesis titulada "Plan estratégico de Márketing para el incremento de la participación en el mercado de la empresa BRITO - S.A. de la ciudad de Guayaquil”, llevada a cabo en la Universidad Politécnica Salesiana, Ecuador, con la finalidad de obtener el título de Ingeniería comercial con mención en Marketing; hace énfasis a lo siguiente; "Diseñar un plan estratégico de márketing destinado en el incremento de la participación en el mercado de la empresa BRITO S.A.”.

La investigación es descriptiva propositiva, donde se usó como técnicas de recolección de datos a la encuesta y entrevista, obteniendo las siguientes conclusiones:

Debido a un buen plan de marketing implementado a través de redes sociales con reuniones periódicas y seguimiento del mismo, se logró el incremento del 3\% de la participación en el mercado y mantenerse en el mismo. Una buena promoción de marketing y el seguimiento permiten brindar valor agregado a las exigencias del cliente. Es decir, con el mejoramiento de la oferta de servicios que ofrece la empresa en cuanto a mejorar la capacidad de cobertura de atención y ampliar la capacidad de abastecimiento del servicio, va a permitir tener mejor demanda del mismo, y así mismo, mejorará la competencia en cuanto a incrementar su cartera de clientes y sus ventas en relación a otras empresas.

Además, se concluyó que es importante escuchar al cliente para mejorar los servicios ofrecido y tener una mayor fidelización de clientes, permitiendo a la empresa permanecer en el mercado por muchos años.

Grandi, (2013), en su trabajo de investigación de tesis titulada "El uso de las redes sociales como estrategia de marketing en empresas del sector hotelero: una revisión del estado del arte", llevada a cabo en la Universidad Politécnica de Valencia, España, con 
la finalidad de obtener el título de Máster; hace énfasis a lo siguiente; "Evaluar el uso de las redes sociales como estrategia de marketing en la empresa del sector hotelero". La investigación es propositiva, donde se usó como muestra a tres empresas del sector hotelero, obteniendo las siguientes conclusiones:

La promoción en redes sociales es una forma de marketing que usualmente usan las empresas como clave de éxito de su negocio, incluso, ayuda en tener una mejor ventaja competitiva. Además, las redes sociales, permiten que las actividades realizadas por las empresas tomen ventaja del capital social en línea que ofrecen las redes sociales y convertirán al marketing en uno de los elementos más importantes en cualquier empresa de servicios.

Se observa que debido al incremento del tiempo de las personas en las redes sociales influye positivamente en la comunicación entre la empresa y clientes a través de éstos medios y ayuda a alcanzar y abrir una buena cartera de clientes. Para ello es necesario escuchar las exigencias del cliente para ir innovando los servicios que oferta la empresa. Entre las más usadas tenemos el Facebook, Twitter y otras redes como alternativas de promoción accesibles.

Es decir, las redes sociales cambiaron la forma en que se realizan las actividades en el sector hotelero, lo que generó el logro en cuanto a los objetivos, estimando el comportamiento de las personas y presenciando de antemano el incremento del tiempo en las redes sociales de las mismas y ampliando una nueva cartera de clientes.

Solórzano y Valle (2016), en su trabajo de investigación de tesis titulada "Estrategias de marketing para mejorar la participación de mercado de la empresa NIVISA en la ciudad de Guayaquil año 2016", llevada a cabo en la Universidad Laica Vicente Rocafuerte de Guayaquil, Ecuador, con la finalidad de obtener el título de Márketing; hace énfasis a lo siguiente; "Diseñar un plan de márketing destinado en incrementar la participación en el mercado de la empresa NIVISA.”.

La investigación es descriptiva propositiva, donde se usó como técnicas de recolección de datos a la encuesta y entrevista, obteniendo las siguientes conclusiones:

El 75\% de los encuestados prefieren que la publicidad de los servicios y productos que oferta Univisa, se la realice de manera televisiva. Puesto que no todas las personas están muy familiarizadas con el uso de la tecnología, o al realizarlo solo visitan páginas específicas las cuales no siempre son redes sociales. De esta manera tendrán mayor 
posibilidad de enterarse acerca de Univisa. Es decir, no siempre las redes sociales son elementos clave de promoción de los servicios que ofrece una empresa ya que depende de la realidad de cada lugar donde se encuentre la empresa. Estas funcionan sólo donde los clientes estén familiarizados con la tecnología y redes sociales, para ello se deben adoptar otras medidas promocionales para tener una mayor participación en el mercado de las empresas.

Además, los encuestados en la presente investigación mencionaron la importancia de innovación de los servicios que ofrece la empresa y emplear medios publicitarios accesibles a ellos, con mayores variedades y buena calidad en los servicios ofertados. Es decir, las estrategias de promoción deben ser efectivas, de acuerdo a cada realidad para incrementar la participación en el mercado de las empresas.

\section{Nacionales}

Carrión (2015), en su trabajo de investigación de tesis titulada "Redes sociales y la promoción de hoteles en el distrito de Andahuaylas, 2015", llevada a cabo en la Universidad Nacional José María Arguedas Andahuaylas, Perú, con la finalidad de obtener el Título Profesional de Licenciado en Administración de Empresas; hace énfasis a lo siguiente; "determinar la relación que existe entre el uso de las redes sociales y la promoción de hoteles en el Distrito de Andahuaylas".

La investigación fue aplicada con un diseño de investigación no experimental, muestra estuvo conformado por 29 hoteles, la misma que estuvo sujeto a través de una encuesta y cuestionario como instrumento de recolección de datos y esta fue analizada a través de cuadros estadísticos, obteniendo las siguientes conclusiones:

Las redes sociales en lo que respecta a los hoteles en el presente distrito de estudio fue sometido a la prueba estadística Rho Spearman lo que evidenció una correlación de 0,675; determinando que existió una relación positiva. El uso de Facebook, Twitter en la promoción de hoteles demostró una relación positiva por lo que hoy en día es de vital importancia para poder llegar a los clientes. Demuestra que sí existe una buena correlación en el uso de redes sociales con la participación en el mercado.

El uso del Facebook es una buena herramienta de promoción de los servicios que ofrece una empresa, con una correlación positiva en la participación del mercado, ya que tiene una relación directa con el cliente, ampliando la cobertura de los mismos en otros lugares. 
Malpica (2016), en su trabajo de investigación de tesis titulada "Grado de eficacia de la estrategia de personalización de marketing digital de la empresa Pinkberry Perú en la red social Instagram, Trujillo 2016", llevada a cabo en la Universidad Privada Antenor Orrego, Trujillo, Perú, con la finalidad de obtener el Título Profesional de licenciado en ciencias de la comunicación; hace énfasis a lo siguiente; "determinar el grado de eficacia de la estrategia de personalización de marketing digital de la empresa Pinkberry.”.

La investigación fue descriptiva correlacional, la muestra estuvo conformada con las personas que se involucran en las redes sociales de Instagram, la misma fue analizada en base a la técnica de fichaje.

Por lo que llegaron a concluir que las estrategias que aplica Pinkberry a través del instagram fueron positivas, esto se debió a su nivel de interactividad en la obtención de respuestas por parte de los usuarios. Por otro lado, el grado de interactividad de los usuarios con lo que presentan la organización tiene un gran crecimiento lo que determina a la audiencia a lograr un alto grado de participación.

Quiere decir que la promoción en redes sociales de acorde al tipo de bien o servicio que ofrezca la empresa y de acuerdo al público objetivo mejora visiblemente la demanda de los servicios. Sin embargo, es necesario escuchar a los clientes para innovar los servicios que se ofrecen y ampliar la cartera existente, de esa manera mejorar la competitividad y la participación en el mercado de las empresas.

Palomino (2016), en su trabajo de investigación de tesis titulada "Estrategias de marketing y la participación de mercado de la línea de toallas higiénicas Nosotras de la empresa DISGOM E.I.R.L en la ciudad de Huánuco-2015", llevada a cabo en la Universidad de Huánuco, Perú, con la finalidad de obtener el Título Profesional de Licenciado en Administración de Empresas; hace énfasis a lo siguiente; "determinar como el influyen las estrategias de marketing en la participación mercado de la línea de toallas higiénicas Nosotras de la empresa DISGOM E.I.R.L.”.

La investigación es descriptiva explicativa, muestra estuvo conformado por 40 bodegas distribuidoras de toallas Nosotras, la misma que estuvo sujeto a través de una encuesta, obteniendo las siguientes conclusiones:

Las estrategias de marketing sí influyen en la participación mercado de la línea de toallas higiénicas Nosotras de la empresa DISGOM E.I.R.L. Se evidencia la importancia de la aplicación de las estrategias para incrementar las ventas y así lograr mayor participación 
en el mercado, y en el segundo se determina la participación del mercado ligada a la alta rotación del producto.

Se determinó que la promoción es también un factor importantísimo a considerar en las empresas, a mayor uso del merchandising, y herramientas promocionales permita un mayor incremento en las ventas, lo cual es beneficioso ya que incrementa su participación en el mercado.

Además, es importante el abastecimiento de los servicios ofrecidos y la cobertura es importante para que el cliente tenga a su alcance los servicios a la hora que necesite en forma eficiente.

\subsubsection{Bases teóricas}

\section{Promoción}

Sanagustín (2017), menciona que promoción es una pieza necesaria para conocer nuevos productos, notas de prensa y concursos de los bienes o servicios que ofrezca una empresa, independientemente del giro del negocio. Pero sobre todo recuerda que debe existir coherencia entre lo publicado y la realidad de la organización, y éstas deben ser muy cuidadosas con el material que se va a publicar. Además, éstas deben ser gradual, ya que demasiada promoción puede alejar a los clientes, y sobre todo debe innovarse a siempre (p. 49-51).

Chong, Aizpuru, y Cárdenas (2007), sostiene que llamamos promoción a las técnicas específicas empleadas para informar y al mismo tiempo persuadir al consumidor por encima de las características y beneficios de los productos y servicios, cualquiera sea el giro de negocio. Y, por último, debe señalarse que las técnicas de promoción no son excluyentes sino complementarias. De allí que una campaña de publicidad en medios masivos (televisión, radio, prensa o anuncios exteriores) siempre requerirá el apoyo de una promoción (p. 22-24).

\section{Tipos de promoción}

Chong et al (2007), hace énfasis a las diferentes estrategias en promoción de ventas que conllevan distintos objetivos. Es decir, que algunas funcionan bien para un tipo de producto y otras no; o bien, dos promociones pueden obtener el mismo resultado, 
pero una con un costo menor que la otra. Todas son diferentes de acuerdo a las realidades de cada país (p. 31).

\section{Redes Sociales (un fenómeno global)}

Neira (2013), son aquellas que conectan a las personas, hace tener una interacción directa con individuos a travez de las publicaciones, todas sin excepción comparten tres aspectos o también denominadas características principales:

Son servicios basados prácticamente en la web: Se desarrollan en un ambiente (online e interactivo). Debido al enorme desarrollo de la tecnología, el acceso en redes es cada vez mayor en dispositivos móviles y en pantallas cada vez más reducidas, sin perder la misma resolución de las imágenes. Esto que implica que cada vez son más usuarios que se encuentran en la comodidad de tener un móvil para ver todo lo que el mundo ofrece en las redes (p. 11-12).

Permiten a los individuos desarrollar un perfil público o semipúblico dentro de un sistema compartido con otros sujetos: Esa identidad digital que un individuo construye es un elemento esencial y clave. A la persona ya no solo le define lo que es (elementos sociodemográficos tradicionales como edad, sexo, nivel de instrucción o clase social). Por lo tanto, el gran activo de las redes sociales hoy en día es la prescripción personal. Es decir, cada usuario deja una impresión sobre aquello que declara que le gusta, que retuitea o que comparte. A diferencia del contenido publicitario que llega precisamente a través de canales convencionales, el que un usuario recibe a través de otro en una red social llega con una tarjeta de presentación adicional. (p. 13)

\section{Redes sociales}

Valls (2016), coincide con otros autores en que una red social es un lugar en la web cuyo objetivo es permitir a los clientes relacionarse, y no solo eso, sino que también comunicarse, compartir contenidos y crear comunidades, como una herramienta que facilita la democratización de las informaciones que precisamente transforma a los individuos en receptores y al mismo tiempo en productores de contenidos. Estas permiten a los usuarios:

- Construir básicamente un perfil público o semi-público dentro de un sistema limitado.

- También articular una lista de usuarios con los que compartir informaciones y establecer una conexión. 
- Visualizar y rastrear su lista de contactos y las de otros usuarios dentro del sistema.

Ante todo, este compendio, podemos mencionar que las redes sociales online como grupo de individuos que comparten esencialmente intereses comunes, se relacionan, comparten informaciones, participaran y demuestran su actividad a través de plataformas de internet, donde tienen lugar los encuentros sociales, y muestran sus gustos y preferencias. Es decir, es la forma más sencilla de relacionarse y sobre todo de compartir con los demás; de manera libre y en tiempo real, los gustos y preferencias, expresando una determinada identidad (p. 27-28).

\section{Tipos de redes sociales}

Valls (2016), menciona que existen varias clasificaciones de las redes sociales. La primera clasificación que establece es la siguiente:

- Redes sociales (offine o analógicas): Sostiene que son las que no requieren de la intermediación de un aparato o sistema electrónico.

- Redes sociales (online o digitales): Son todas aquellas que se gestión a través de cualquier medio electrónico.

- Mixtas: En este punto trata de una combinación de ambas, de las cuales ya se mencionó en líneas anteriores.

Asimismo, afirma que existe otro tipo de clasificación que se basa fundamentalmente en la información que se comparte y la relación entre los usuarios, distinguiéndose de la siguiente manera:

1. Redes sociales directas: Son todas aquellas en las que los usuarios pueden contralar la información que comparten a través de la red. Por lo tanto, existe una colaboración entre grupos de individuos que comparten los mismos intereses comunes, pero que interactúan en total igualdad de condiciones. Frente a esta situación surge:

a. Según su finalidad: Es decir, teniendo en cuenta el objetivo que persigue el usuario, pueden ser:

i. De ocio: Manifiesta que solo se persiguen determinados objetivos y mejora de las relaciones personales a través de la interacción con otros usuarios, 
comunicándose con ellos, realizando comentarios o compartiendo informaciones.

ii. De uso profesional: El usuario busca principalmente promocionales a nivel profesional, estar al día en su campo o especialidad e incrementar su agenda de contactos. (p. 29)

b. Según el modo de funcionamiento: Es decir, teniendo en cuenta el conjunto de procesos que estructuran las redes sociales y las orientan hacia actividades concretas. En este caso se subdividen en:

i. Redes sociales de contenidos: Son aquellas en las que el usuario crea contenidos, ya sea en soporte escrito o audiovisual y, posteriormente, lo distribuye y comparte a través de la red social. Aquí no hay necesidad de la creación de un perfil.

ii. Redes sociales basadas en perfiles: Son aquellas en las que los usuarios crean perfiles y colocan información personal, incluyendo datos generales o específicos del usuario.

c. Según el grado de apertura: Es decir, teniendo en cuenta la capacidad de acceso a las mismas por cualquier usuario, se subdividen en:

i. Redes sociales públicas: Son aquellas que están abiertas a ser empleadas por cualquier tipo de usuario que cuente con un dispositivo de acceso a internet, sin necesidad de pertenecer a un grupo u organización.

ii. Redes sociales privadas: Son aquellas que son restringidas y sólo pueden acceder determinados grupos específicos o usuarios que están unidos o son amigos. Los usuarios suelen mantener relación contractual o de otra índole con dicho grupo. (p. 30)

d. Según el nivel de integración; es decir, teniendo en cuenta el nivel de afinidad, interés e involucración en determinadas materias o actividades, se clasifican, a su vez, en:

i. Redes sociales de integración vertical: Su empleo suele estar acotado al uso por parte de un grupo de usuarios a los que une una misma formación, interés o pertenencia profesional. Suele ser frecuente acceder a ellas por invitación 
de un miembro y la información aportada en los perfiles suele ser comprobada y verificada, pudiendo, en muchas ocasiones, ser de pago.

ii. Redes sociales de integración horizontal: Su empleo no está acotado a un grupo de usuarios con intereses comunes en una determinada materia. (p. 3031)

\section{Promoción de redes sociales}

Según Reales, Bohórquez y Rueda (1993), es la forma en que conceptualizamos a un sistema humano abierto, cooperativo y de propósito constructivo que mediante un intercambio dinámico, ya sea de energía, materia e información de sus integrantes logra la potenciación de sus recursos (Citado en Carrión, 2015 p. 51). Actualmente, las más utilizadas por las empresas son: El facebook, páginas web, y Fanpage, entre otras.

Ibañez (2014), las redes sociales de Internet no dejan de ser un reflejo del entramado de relaciones sociales de la "vida real", un conjunto de individuos/organizaciones conectados por algún tipo de relación que se comunican entre sí (p. 11).

Observatorio Regional de la Sociedad de la Información de Castilla y León [ORSI], (2012) La información se puede presentar en varias formas (escrita, audiovisual), y se permite que el usuario cree su propio contenido. En este nuevo entorno las empresas deben conversar, ya no basta con comunicar y esperar la respuesta de sus clientes. Ahora se necesita conversar con éstos y que nos ayuden a conocer la utilidad de nuestros productos y servicios, que nos transmitan sus vivencias en el uso y que nos ayuden a innovar y a adaptarlos para satisfacer sus necesidades. (p. 25-26).

\section{Características principales de la promoción de las redes sociales}

Observatorio Regional de la Sociedad de la Información de Castilla y León (ORSI, 2012), señala que existe tres características fundamentales de las cuales se menciona a continuación:

- El intercambio permanente de información.

- La inmediatez de este intercambio.

- Las relaciones ente los usuarios como elementos clave. (p. 26)

\section{Evaluación de la promoción de redes sociales}

Observatorio Regional de la Sociedad de la Información de Castilla y León 
(ORSI, 2012) sostiene que las redes sociales se han convertido en uno de los medios más efectivos para promocionar una marca con unos resultados muy superiores a los obtenidos en los medios tradicionales. Como puede observarse en la siguiente ilustración una gran parte de la audiencia online española se vincula a las redes sociales (Social Media) (p. 14).

\section{Facebook}

Observatorio Regional de la Sociedad de la Información de Castilla y León (ORSI, 2012, p. 28-29), da a conocer que ésta herramienta es utilizada a nivel mundial, tiene la propiedad de subir imágenes, videos y por ende crear grupos, la misma que destaca por contar una diversidad de aplicaciones totalmente sofisticadas.

a. Foto: Alternativa que se utiliza para reconocer el nombre, fachada o producto más mediáticos del negocio.

b. Información: Escribe una nota publicitaria breve que describe claramente en que consiste tu negocio y añade enlaces útiles e información de contacto.

c. Publicaciones en el muro: Agrega periódicamente actualizaciones, fotos, videos y enlaces sobre tu negocio en tu muro. Esto aparecerán en la selección de noticias, donde tus fans y sus amigos podrán comentarlos y compartirlos.

\section{Twitter}

Observatorio Regional de la Sociedad de la Información de Castilla y León (ORSI, 2012, p. 43), hace mención que es un servicio totalmente gratuito de microblogging, que tiene como papel ser la red social que permite a los usuarios en publicar o enviar mensajes basados en texto, por lo que se conoce como "tweets"; tales se muestran en la página de perfil de forma inmediata.

a. Página de bienvenida: esta es diseñada para establecer una concientización y por ende crear y generar interés sobre nuestra marca. El mensaje publicitario es por lo general cargada en la página principal del usuario. Esta página es dirigida a determinados usuarios y presenta una segmentación sociodemográfica lo que hace mención la edad, sexo, provincia.

b. Página de bienvenida con video: Por lo general esta es diseñada para crear una conciencia sobre la marca y de antemano generar interés. Esta es cargada en la página de inicio al inferior de cada pantalla. 


\section{YouTube}

Observatorio Regional de la Sociedad de la Información de Castilla y León (ORSI, 2012, p. 59) da a conocer que YouTube es la comunidad de videos más conocida a nivel nacional como internacional, donde el gran número de usuarios pueden visualizar, dejar comentarios y subir sus propios videos. Asimismo, es reconocida como una plataforma perfecta para realizar acciones de video-marketing.

- Personalización: La tecnología permite enviar comunicaciones que contienen los datos personales del remitente, lo que contribuye a que exista una mayor identificación.

- Segmentación: Los receptores pueden ser clasificados según criterios determinados por parte de los clientes.

- Interacción: por medio de los mensajes de texto se pueden predecir las acciones que ejecutan en reacción a los clientes.

\section{Páginas web.}

Son utilizadas comúnmente por las empresas para publicitar las ofertas en bienes o servicios. Incluso se utilizan para publicitar la imagen de artistas, entre otros.

\section{Fanpage.}

Es otra herramienta de promoción que utilizan las empresas o personas con negocio para ofertar productos, bienes o servicios a los diferentes contactos del público unidos en redes sociales.

\section{Participación en el mercado}

Se refiere al porcentaje que una empresa tiene del mercado, expresado en unidades del mismo tipo o el volumen de ventas explicado en valores monetarios de un producto o servicio específico (Palomino, 2016).

Kotler y Keller (2012, p. 37), sostiene que los consumidores han encontrado una voz amplificada para influir en la opinión de sus similares y en la opinión pública. Las empresas han reconocido esto y los invitan a participar en el diseño e incluso en la comercialización de ofertas para aumentar su sentido de pertenencia y conexión. Los consumidores perciben a sus empresas favoritas como talleres de los que pueden obtener las ofertas que desean. 
Ferrel y Hartline (2012), da a conocer que es la colaboración de los clientes, la misma que corresponde a las ventas que fueron determinados a efecto de otras empresas que generan la misma actividad en el mercado. Asimismo, es uno de los principales indicadores de ocupación de una entidad en contraposición a sus competidores, tiende a analizar la propensión y tendencias del mercado.

Kotler y Keller óp cit. (2012), señala que ttradicionalmente, un "mercado", era una ubicación física donde se reunían compradores y vendedores para comprar y vender bienes. Los economistas describen el mercado como el grupo de compradores y vendedores que realizan transacciones sobre un producto o clase de productos (como el mercado de vivienda o el mercado de granos) (p. 32).

\section{Estrategias de crecimiento para la participación del mercado}

Luego del análisis de la teoría expuesta por Alcaide, Díaz y Espinoza (2013) el cual dedujo tres estrategias de participación en el mercado. (p. 78).

- Estrategia de penetración en el mercado. Se considera como opción de crecimiento por parte de la empresa tomando en cuenta los productos con lo que la empresa trabaja.

- Estrategia de desarrollo del mercado. Involucra en adquirir nuevas técnicas para el producto, asimismo estas son utilizadas a través de canales de distribución en diferentes áreas geográficas.

- Estrategia de desarrollo del producto. Lanzamiento de nuevos modelos y tendencias en lo que respecta a bienes de menor precio y calidad.

- Estrategia de diversificación. Ocurre cuando la empresa desarrolla, de forma compatible, nuevos productos y nuevos mercados.

Ferrell y Hartline (2012), mencionan que existen Cinco orientaciones básicas sobre las estrategias del producto - mercado, las cuales son descritas a continuación:

\section{El paso del segmento}

En los años venideros, en el área del producto-mercado el problema principal de los de las personas que son comerciantes deberá ser la de restringir el segmento más apropiado para cada uno de sus bienes (productos), y servicios como consecuencia de una paulatina y cuidadosa segregación de los mercados, refinado y preciso posicionamiento de sus ofertas, ello permitirá responder a demandas, exigencias y 
perspectivas cada vez más personalizadas de los clientes finales, que demandarán productos y servicios elaborados casi a la medida de cada uno de ellos (Ferrell y Hartline, 2012).

\section{Centro de atención de las estrategias}

El centro de atención de las estrategias deberá centrarse en tres áreas clave: el consumidor (como individuo), los competidores y los canales de distribución, es decir analizar las necesidades de los clientes y reconocer lo que requieren, las estrategias utilizadas por los consumidores, y cuáles serán los medios determinados para realizar la operación de comercialización de los productos. (Ferrell y Hartline, 2012).

\section{Los objetivos de los productos/servicios.}

Las líneas de acción estratégica, inducen los bienes y servicios según la oferta integral de las empresas, asimismo cada uno de estos, pueden desarrollarse de manera independiente y posicionarse en el mercado (Ferrell y Hartline, 2012).

\section{Cobertura de los mercados}

La cobertura de los mercados estará relativamente direccionada a ser selectiva con el objetivo de responder al transcurso de segmentación del mercado en espacios cada vez más pequeños y al posicionamiento distinguido para los productos y/o servicios. Ferrell y Hartline (2012).

\section{Globalización}

En cuanto a la globalización las tendencias dan a conocer que el marketing nacional como internacional tiende a deslizarse en base a juicios y orientaciones según la participación frente al mercado. Ferrell y Hartline (2012).

Según Palomino (2016), menciona tres dimensiones de la participación en el mercado y son:

- Oferta. Según Kotler, Armstrong, Cámara y Cruz (2004), refiere a la oferta como la combinación de bienes, servicios, información o experiencias para satisfacer una necesidad o problema en la población (Citado en Palomino, 2006, p. 36).

- Demanda. Según Gregory Mankiw, (2010), la demanda en economía “es la cantidad y calidad de bienes y servicios que pueden ser adquiridos a los diferentes precios del mercado por un consumidor" (Citado en Palomino, 2006, p. 37). 
- Competencia. Según Fernández (2010), la competitividad en los negocios es lograr y mantener una buena rentabilidad igual o superior a la de su competencia en el mercado. De lo contrario las empresas no podrían ser sostenibles en el tiempo. Para ello existen elementos como la capacidad financiera, métodos y la capacidad de ser fuertes para sobrevivir (Citado en Palomino, 2006, p. 38).

\subsection{Definición de términos básicos}

\section{Promoción}

Sanagustín (2017), menciona que promoción es una pieza necesaria para conocer nuevos productos, notas de prensa y concursos de los bienes o servicios que ofrezca una empresa, independientemente del giro del negocio. Pero sobre todo recuerda que debe existir coherencia entre lo publicado y la realidad de la organización, y éstas deben ser muy cuidadosas con el material que se va a publicar. Además, éstas deben ser gradual, ya que demasiada promoción puede alejar a los clientes, y sobre todo debe innovarse a siempre (p. 49-51).

\section{Redes Sociales (un fenómeno global)}

Neira (2013, p. 11), sostiene que todos conocemos o al menos tenemos una idea de ejemplos de redes sociales. Pero realmente ¿sabemos y conocemos qué son en sí? Es probable que nunca nos hayamos parado a reflexionar sobre ello, pero si entendemos su concepto y filosofía comprendemos el valor esencial que pueden aportar a una empresa u organización.

\section{Promoción de redes sociales}

Según Reales, Bohórquez y Rueda (1993), es la forma en que conceptualizamos a un sistema humano abierto, cooperativo y de propósito constructivo que, mediante un intercambio dinámico, ya sea de energía, materia e información de sus integrantes logra la potenciación de sus recursos (Citado en Carrión, 2015 p. 51).

\section{Participación de mercado}

Se refiere al porcentaje que una empresa tiene del mercado, expresado en unidades del mismo tipo o el volumen de ventas explicado en valores monetarios de un producto o servicio específico (Palomino, 2016). 


\section{CAPÍTULO II \\ MATERIALES Y MÉTODOS}

\subsection{Sistema de hipótesis}

\subsubsection{Hipótesis}

\section{General}

Hi: La promoción en redes sociales se relaciona significativamente con la participación en el mercado de la Asociación Peruana de Agencias de Viajes y Turismo San Martín APAVIT, en el distrito de Tarapoto, 2017.

Ho: La promoción en redes sociales no se relaciona significativamente con la participación en el mercado de la Asociación Peruana de Agencias de Viajes y Turismo San Martín - APAVIT, en el distrito de Tarapoto, 2017.

\section{Específicas}

H1: La promoción en redes sociales se relaciona significativamente con la oferta inherente a la participación en el mercado de la Asociación Peruana de Agencias de Viajes y Turismo San Martín - APAVIT, en el distrito de Tarapoto, 2017.

H2: La promoción en redes sociales se relaciona significativamente con la demanda inherente a la participación en el mercado de la Asociación Peruana de Agencias de Viajes y Turismo San Martín - APAVIT, en el distrito de Tarapoto, 2017.

H3: La promoción en redes sociales se relaciona significativamente con la competencia inherente a la participación en el mercado de la Asociación Peruana de Agencias de Viajes y Turismo San Martín - APAVIT, en el distrito de Tarapoto, 2017.

\subsection{Sistemas de variables}

Variable 1: Promoción en redes sociales. Según Reales, Bohórquez y Rueda (1993), es la forma en que conceptualizamos a un sistema humano abierto, cooperativo y de propósito constructivo que, mediante un intercambio dinámico, ya sea de energía, materia e información de sus integrantes logra la potenciación de sus recursos (Citado en Carrión, 2015 p. 51). 
Variable 2: Participación de mercado. Se refiere al porcentaje que una empresa tiene del mercado, expresado en unidades del mismo tipo o el volumen de ventas explicado en valores monetarios de un producto o servicio específico (Palomino, 2016).

\subsection{Tipo de métodos de la investigación}

\subsubsection{Tipo y nivel de investigación}

Acorde al planteamiento de Hernández, Fernández y otros (2014) respecto de los tipos de investigación es de la siguiente manera:

Por su finalidad es aplicada, puesto que utilizando ciencia establecida y el criterio del investigador que busca obtener resultados que nos permitirán comprobar la hipótesis.

Por su contrastación es descriptiva, debido a que la investigación se fundamenta en leyes y teorías científicas orientando a encontrar la relación de las variables de estudio, identificadas y explicadas en la formulación de las hipótesis en la investigación, estas que se fundamentan en parámetros y constantes que dan consistencia al desarrollo de la investigación.

\subsection{Diseño de investigación}

\subsubsection{Diseño de investigación}

La investigación es no experimental, debido que a través de esta metodología no se manipularan deliberadamente las variables, asimismo esto da a conocer a que el estudio se basará fundamentalmente en la observación directa de la problemática a través de contexto natural para posteriormente ser analizados. Hernández Fernández y Baptista (2010).

\section{Será un diseño Descriptivo Correlacional:}

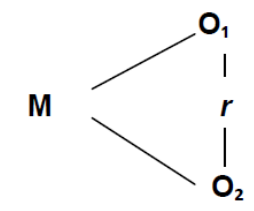

\section{En donde:}

$\mathrm{M}=$ Muestra 
$\mathrm{X}=$ Promoción en redes sociales

Y = Participación de mercado

$\mathrm{r}=$ relación

\subsection{Población y muestra}

\section{Población}

La población está constituida por las agencias de viajes asociadas a APAVIT San Martin, mismas que constituyen un total de 23 agencias de viajes en la provincia de San Martín (APAVIT, 2017).

\section{Muestra}

La muestra está conformada por 16 agencias de viajes asociadas y activas en APAVIT San Martín, en el distrito de Tarapoto.

El tamaño de la muestra está en relación directa con la desviación típica de las puntuaciones en las características de las variables estudiadas. De las cuales para muestras menores o iguales a $50(\mathrm{~N}<50)$ se utiliza el coeficiente de correlación de Pearson y las consideraciones estadísticas que se tuvo en cuenta para obtener un nivel de confiabilidad precisa en este caso las 16 agencias de viajes que participan directamente en APAVIT San Martín, y que están ubicadas dentro de la jurisdicción del distrito de Tarapoto. 


\section{CAPÍTULO III RESULTADOS DE LA INVESTIGACIÓN}

\subsection{Técnicas de recolección de Datos}

\section{Técnicas:}

Para el presente trabajo de investigación se empleó como técnica la encuesta, que se aplicó a los gerentes de las agencias viajes asociadas a APAVIT en el distrito de Tarapoto. El número de encuestas fue definido por la cantidad de agencias de viajes activas en APAVIT San Martín.

La investigación es cuantitativa ya que tiene como objetivo obtener respuestas de la muestra a preguntas específicas cerradas, ya que se quiere obtener datos numéricos para analizar y comprobar la información de una forma concreta, decisiones exactas de correlación de las agencias asociadas, por lo que se utilizó como técnica la encuesta a los socios de APAVIT San Martin.

\section{Instrumentos:}

Para la recolección de los datos se utilizó como instrumentos dos cuestionarios referidos a las variables de la investigación tanto de la promoción en redes sociales y las participaciones del mercado de las agencias de viajes asociadas y activas en APAVIT San Martín.

Escala tipo Likert. Este es un tipo de instrumento de medición o de recolección de datos que se dispone en la investigación social para medir actitudes. Dentro de los aspectos constitutivos de la escala tipo ordinal, es importante resaltar los índices, las alternativas o puntos que corresponden a las opciones de respuesta de acuerdo al instrumento seleccionado (Málave, 2007). En este caso se asignó un peso a cada resultado, lo cual permitió una ponderación final por cada indicador direccionando a una interpretación como conclusión de 1 a 5 o como disponga el investigador.

\section{Validación y confiabilidad de los instrumentos:}

La validez es la mejor aproximación a la "verdad", que puede tener una proposición, apunta a sostener cuan legitimas son las proposiciones o ítems que conforman el cuestionario. Ha sido elaborado por los autores y validado mediante 08 encuestas 
piloto que fueron aplicadas en la ciudad de Moyobamba a los socios del gremio AVITUR Alto Mayo. Su estructura comprende 12 y 6 ítems distribuidos en los cuestionarios de las variables 1 y 2 respectivamente según las dimensiones e indicadores, cada uno de los cuales permite estimar cinco posibilidades de respuesta, Muy malo, Malo, regular, bueno y muy bueno.

V1: Confiabilidad de la promoción en redes sociales: para la obtención de la confiabilidad de la variable Promoción en redes sociales se aplicó la fórmula del coeficiente alfa de Cron Bach, donde se deben obtener resultados iguales o parecidos dentro de un rango razonable, donde el resultado en este caso tuvo un valor de muy bueno con referencia al instrumento aplicado a la prueba piloto.

\begin{tabular}{|l|l|}
\hline Confiabilidad & \\
\hline Alfa & 0.955280 \\
\hline
\end{tabular}

V2: Confiabilidad de participación en el mercado: para la obtención de la confiabilidad de la variable de Participación en el mercado se aplicó la fórmula del coeficiente alfa de Cron Bach, donde se deben obtener resultados iguales o parecidos dentro de un rango razonable, donde el resultado en este caso tuvo un valor de muy bueno con referencia al instrumento aplicado a la prueba piloto.

\begin{tabular}{|l|l|}
\hline Confiabilidad & \\
\hline Alfa & 0.823708 \\
\hline
\end{tabular}

\subsubsection{Técnicas de procesamiento y análisis de datos}

Este proceso se llevó a cabo una vez que se han procesado los datos y comprende los siguientes pasos:

Los datos cuantitativos fueron ordenados y procesados mediante el Microsoft Excel y el programa estadístico SPSS V22; para la presentación y análisis de los datos referidos a cada una de las variables.

Medidas de tendencia central: Comprende la media. 
Medidas de variabilidad o dispersión: Los datos fueron distribuidos en el diagrama de dispersión para ver la relación tienen con la media de la población. Esto comprende la desviación estándar, rango, máximo y mínimo valor.

\subsection{Tratamiento estadístico e interpretación de cuadros.}

\subsubsection{Resultados}

A nivel descriptivo

Tabla 1

Medidas Estadísticas descriptivas sobre la promoción de redes sociales y participación en el mercado - 2017.

\begin{tabular}{|c|c|c|}
\hline Medidas & $\begin{array}{c}\text { Participación en el } \\
\text { Mercado }\end{array}$ & $\begin{array}{l}\text { Promoción en } \\
\text { Redes Sociales } \\
\end{array}$ \\
\hline Válido & 16 & 16 \\
\hline Media & 18,44 & 47,00 \\
\hline Desviación estándar & $\pm 1,788$ & $\pm 4,633$ \\
\hline Rango & 6 & 16 \\
\hline Mínimo & 15 & 40 \\
\hline Máximo & 21 & 56 \\
\hline
\end{tabular}

En la tabla 1, se aprecia las medidas estadísticas a nivel descriptivo de ambas variables; notándose que la promoción en redes sociales, se obtuvo una media de 47,00 puntos, con una desviación estándar de \pm 4.63 desviaciones respecto a la media y un rango de 16 puntos; deduciéndose que dichas puntuaciones son homogéneas y poco dispersas. Con respecto a la participación en el mercado, se obtuvo una media de 18,44 puntos, con una desviación estándar de \pm 1.78 desviaciones respecto a la media y un rango de 6 puntos; es decir, las puntuaciones son más homogéneas y poco dispersas.

\section{Tabla 2}

Nivel de promoción de las Redes Sociales - 2017

\begin{tabular}{lcrr}
\hline & Nivel & Cantidad & Porcentaje \\
\hline Alta & $52-60$ & 4 & $25 \%$ \\
\multirow{2}{*}{ Media } & $43-51$ & 10 & $62 \%$ \\
\multirow{2}{*}{ Baja } & $12-42$ & 2 & $13 \%$ \\
& T O T A L & 16 & $100 \%$ \\
\hline
\end{tabular}

Fuente. Elaboración propia a partir de los datos recogidos mediante los instrumentos 
En la tabla 2 y figura 1, se aprecia la cantidad y porcentaje de opiniones de las agencias de viajes asociadas a APAVIT San Martín; notándose que, el 62\% (10) consideran que la promoción en redes sociales es media, con puntajes que oscilan entre 43 y 51 puntos en base a la escala de medición, el 25\% de los asociados a APAVIT San Martín (4) considera que la promoción en redes sociales es alta, con puntuaciones que se ubican entre 52 y 60 puntos y solamente un $13 \%$ de asociados (2) considera que la promoción en redes sociales es baja, con puntuaciones que varían entre 12 y 42 puntos respectivamente.

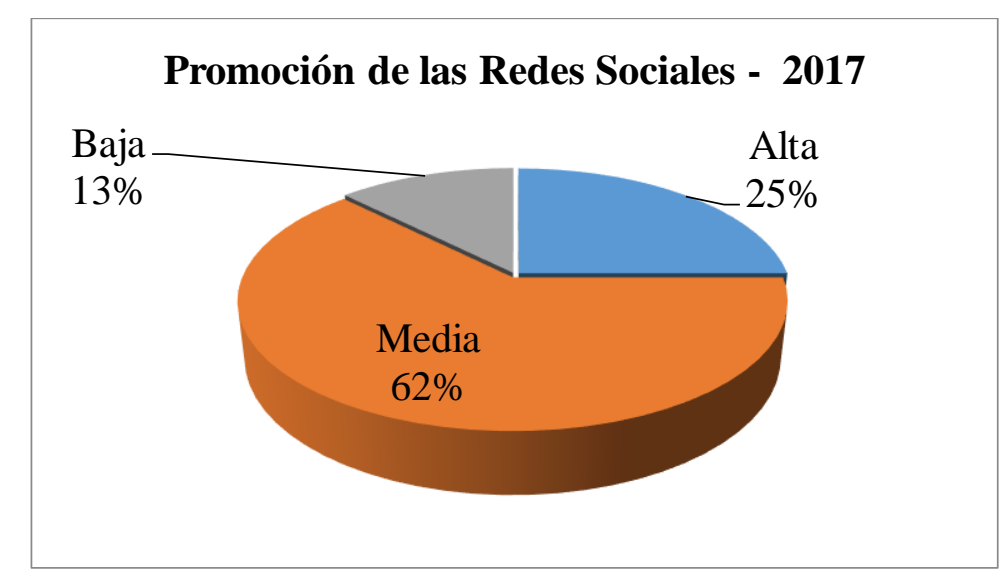

Figura 1. Promoción en redes sociales de las agencias asociadas a APAVIT San Martín, 2017. (Fuente. Elaboración propia a partir de los datos recogidos mediante los instrumentos).

Es decir, se deduce que la promoción en redes sociales de las agencias de viajes asociadas a APAVIT San Martín tiene un nivel medio en lo que concierne a Facebook, página web y Fanpage. Estas agencias de viaje manejan las redes sociales mencionadas a nivel de indicadores como perfiles, publicaciones, comentarios y contactos para promocionar los servicios que ofrecen y tener mejores resultados. Sin embargo, éstas no están siendo muy efectivas ni eficientes con la información y publicaciones que realizan. Quiere decir, que se necesita trabajar dichos puntos para mejorar la promoción en redes sociales y los resultados seas mayores.

\section{Tabla 3}

Nivel de participación en el mercado, 2017

\begin{tabular}{lcrr}
\hline & Nivel & Cantidad & Porcentaje \\
\hline Alta & $19-24$ & 7 & $44 \%$ \\
Media & $13-18$ & 9 & $56 \%$ \\
Baja & $0-12$ & 0 & $0 \%$ \\
& T O T A L & 16 & $100 \%$ \\
\hline
\end{tabular}

Fuente. Elaboración propia a partir de los datos recogidos mediante los instrumentos. 
En la tabla 3 y figura 2, se presenta la cantidad y porcentaje de participación en el mercado de las agencias de viaje asociadas a APAVIT San Martín, distribuidos según la escala de medición para dicha variable; distinguiéndose que, el $56 \%$ (9) mencionan que la participación en el mercado es Media, cuyos puntajes oscilan entre 13 y 18 puntos, el $44 \%$ de los asociados (7) mencionan que la participación en el mercado es Alta, con puntuaciones que oscilan entre 19 y 24 puntos.

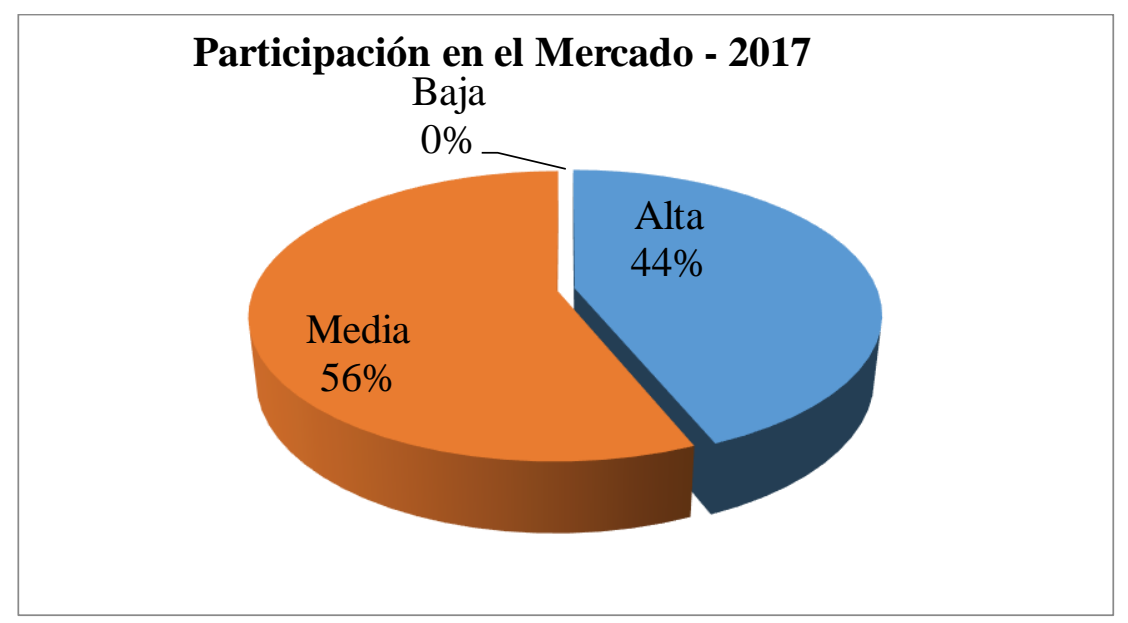

Figura 2. Participación en el mercado de las agencias asociadas a APAVIT San Martín, 2017. (Fuente. Elaboración propia a partir de los datos recogidos mediante los instrumentos).

Gran parte de agencias de viajes (56\%), tienen una participación en el mercado en un nivel medio. Es decir, con respecto a las dimensiones de oferta, demanda y competencia no tienen mayores resultados en la variable de participación en el mercado. Falta mejorar la cobertura en la atención para cubrir las expectativas del cliente, ampliando su cartera de clientes y mejorando sus precios en relación a su competencia para tener nuevos clientes.

\section{A nivel correlacional}

Ahora, en concordancia con el objetivo general, para determinar la relación entre las variables de estudio; se utilizó el coeficiente de correlación de Shapiro Wilk, porque según la prueba de normalidad de Kolmogorov-Smirnov para muestras menores o iguales a 50 sujetos $(\mathrm{N}<50)$ indican que las puntuaciones asignadas para promoción en redes sociales y participación en el mercado no proceden de una distribución normal $(p=200>0,05)$; puesto que, se obtuvo una nivel de significancia de 0,200 para cada uno de los datos de las variables de estudio respectivamente, tal como se aprecia en tabla 4 y los figura respectiva elaborado en el SPSS. 


\section{Tabla 4}

Pruebas de normalidad sobre las puntuaciones de las variables de estudio.

\begin{tabular}{|c|c|c|c|c|c|c|}
\hline & \multicolumn{3}{|c|}{ Kolmogorov-Smirnov ${ }^{a}$} & \multicolumn{3}{|c|}{ Shapiro-Wilk } \\
\hline & Estadístico & Gl & Sig. & Estadístico & gl & Sig. \\
\hline $\begin{array}{l}\text { Participación } \\
\text { Mercado }\end{array}$ &, 153 & 16 & ,200* & ,947 & 16 & , 443 \\
\hline $\begin{array}{l}\text { Promoción } \\
\text { Redes Sociales }\end{array}$ &, 148 & 16 & ,200* & ,959 & 16 & ,645 \\
\hline
\end{tabular}

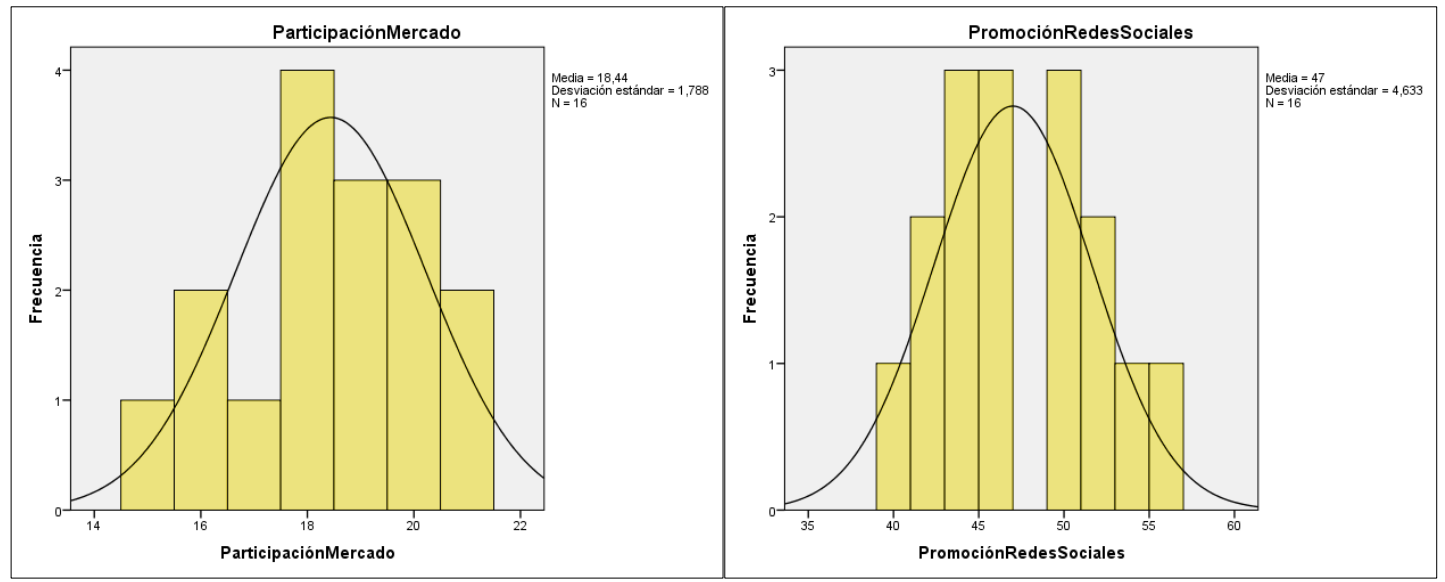

Figura 3. Frecuencia de variables (Fuente. Elaboración propia mediante el procesador SPSS V22 a partir de los datos recogidos mediante los instrumentos).

En la tabla 5 se presentan las correlaciones de pearson y su respectivo nivel de significancia entre los puntajes totales asignados por los sujetos muestrales a cada una de las variables y sus respectivas dimensiones; en concordancia con el objetivo general; pues el grado de correlación entre la promoción en redes sociales y participación en el mercado, es de 0,571; es decir, se obtuvo un grado de correlación muy baja y con dirección positiva, lo cual significa que la promoción en redes sociales de las agencias de viajes asociadas a APAVIT San Martín, con sus dimensiones de Facebook, página web y Fanpage, con sus indicadores de perfiles, publicaciones, comentarios y contactos, inciden directamente en la participación en el mercado. Además, la correlación fue significativa en el nivel 0,010 con un examen estadístico bilateral y de acuerdo a la regla de decisión, frente a un $\mathrm{p}$-valor $(0.010 \leq 0.05)$ se rechaza la hipótesis nula y se concluye que existe una relación directa y significativa entre la promoción en redes sociales y la participación 
en el mercado de las agencias de viajes asociadas a APAVIT San Martín; tal como se aprecia en la figura 4.

\section{Tabla 5}

Correlaciones entre variables y prueba de hipótesis de la promoción en redes sociales y participación del mercado de las agencias de viajes asociadas a APAVIT San Martín2017.

\begin{tabular}{|c|c|c|c|c|c|c|}
\hline \multicolumn{2}{|c|}{ Correlaciones } & \multirow{3}{*}{$\begin{array}{r}\begin{array}{c}\text { Ofer } \\
\text { ta }\end{array} \\
1\end{array}$} & \multirow{2}{*}{\begin{tabular}{|l|}
$\begin{array}{l}\text { Dem } \\
\text { anda }\end{array}$ \\
,- 043 \\
\end{tabular}} & \multirow{2}{*}{$\begin{array}{r}\begin{array}{c}\text { Compete } \\
\text { ncia }\end{array} \\
, 057\end{array}$} & \multirow{2}{*}{$\begin{array}{r}\begin{array}{r}\text { Participa } \\
\text { ción en el } \\
\text { Mercado }\end{array} \\
, 544^{*}\end{array}$} & \multirow{2}{*}{$\begin{array}{c}\begin{array}{c}\text { Promoci } \\
\text { ón en } \\
\text { Redes } \\
\text { Sociales } \\
, 274\end{array} \\
\end{array}$} \\
\hline Oferta & $\begin{array}{l}\text { Correlación de } \\
\text { Pearson }\end{array}$ & & & & & \\
\hline & Sig. (unilateral) & & ,437 & ,417 &, 015 & ,153 \\
\hline Demanda & $\begin{array}{l}\text { Correlación de } \\
\text { Pearson }\end{array}$ &,- 043 & 1 &, 225 &, $571^{*}$ & ,282 \\
\hline \multirow{3}{*}{$\begin{array}{c}\text { Competenci } \\
\mathbf{a}\end{array}$} & Sig. (unilateral) & ,437 & & ,201 & ,010 & ,145 \\
\hline & $\begin{array}{l}\text { Correlación de } \\
\text { Pearson }\end{array}$ &, 057 &, 225 & 1 &, $741^{* *}$ & ,489* \\
\hline & Sig. (unilateral) &, 417 &, 201 & & ,001 & ,027 \\
\hline $\begin{array}{c}\text { Participació } \\
\text { n en el }\end{array}$ & $\begin{array}{l}\text { Correlación de } \\
\text { Pearson }\end{array}$ &, $544^{*}$ &, $571^{*}$ &, $741^{* *}$ & 1 &, $571^{*}$ \\
\hline Mercado & Sig. (unilateral) & ,015 &, 010 &, 001 & & ,010 \\
\hline $\begin{array}{l}\text { Promoción } \\
\text { en Redes }\end{array}$ & $\begin{array}{l}\text { Correlación de } \\
\text { Pearson }\end{array}$ &, 274 & ,282 & ,489* &, $571^{*}$ & 1 \\
\hline \multirow[t]{2}{*}{ Sociales } & Sig. (unilateral) & , 153 &, 145 & ,027 &, 010 & \\
\hline & $\mathrm{N}$ & 16 & 16 & 16 & 16 & 16 \\
\hline
\end{tabular}

*. La correlación es significativa en el nivel 0,05 (1 cola).

**. La correlación es significativa en el nivel 0,01 (1 cola).

Además, el coeficiente de determinación indica que la promoción en redes sociales es explicada por el $1.73 \%$ de la participación en el mercado de las agencias de viajes y la diferencia se infiere que se debe a otros factores o causas ajenas a la variable mencionada. Por tanto, se puede asumir que hay una correlación lineal entre ambas variables de estudio.

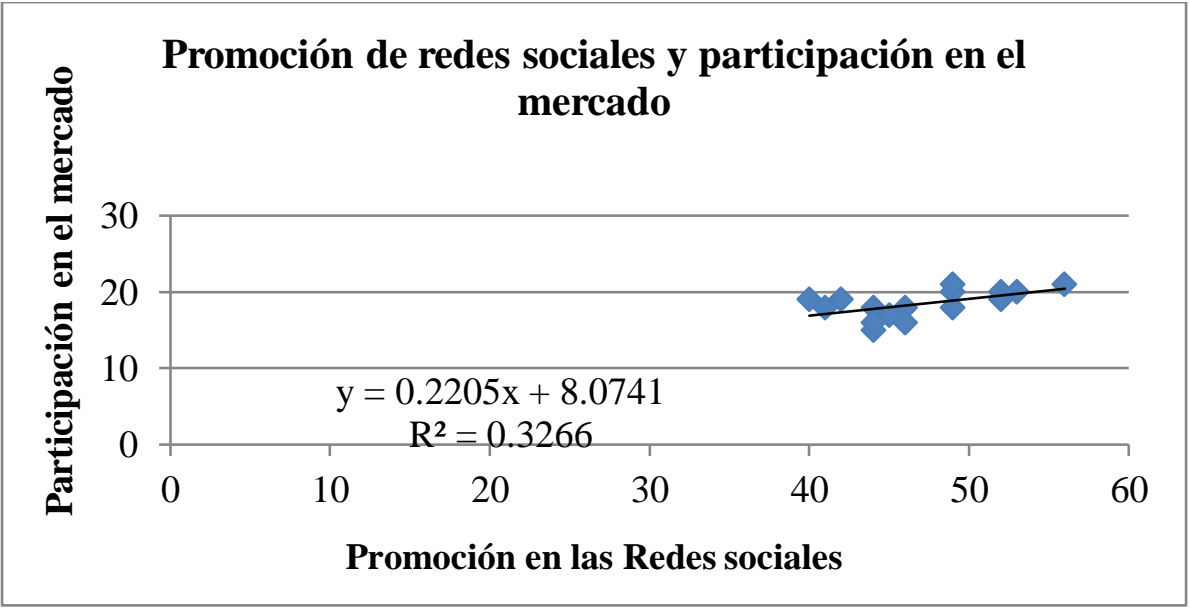


Figura 4. Relación entre la promoción en redes sociales y participación en el mercado de las agencias de viajes asociadas a APAVIT San Martín, 2017. (Fuente. Elaboración propia mediante el procesador SPSS V22 a partir de los datos recogidos mediante los instrumentos).

En concordancia con el primer objetivo específico; se determinó que el grado de correlación entre la promoción en redes sociales con la oferta inherente a la participación en el mercado es 0,274; es decir, se obtuvo un grado de correlación baja y con dirección positiva, lo cual significa que la promoción en redes sociales incide directamente en la capacidad de abastecimiento en servicios y la capacidad de cobertura en la atención. Sin embargo, la correlación es poco significativa; porque el examen estadístico bilateral y de acuerdo a la regla de decisión, frente a un p-valor $(0.153 \geq 0.05)$ se acepta la hipótesis alterna y se concluye que existe una relación directa y poco significativa entre la promoción en redes sociales con la oferta inherente a la participación en el mercado; tal como se aprecia en la tabla 5 y figura 5 respectivamente.

Igualmente, el coeficiente de determinación indica que la promoción en redes sociales con la oferta inherente a la participación en el mercado es explicada por el $0.11 \%$ respecto a la calidad del servicio, y la diferencia se infiere que se debe a otros factores o causas ajenas a la variable mencionada. Por tanto, se puede asumir que hay una correlación lineal y poco significativa entre ambas variables de estudio.

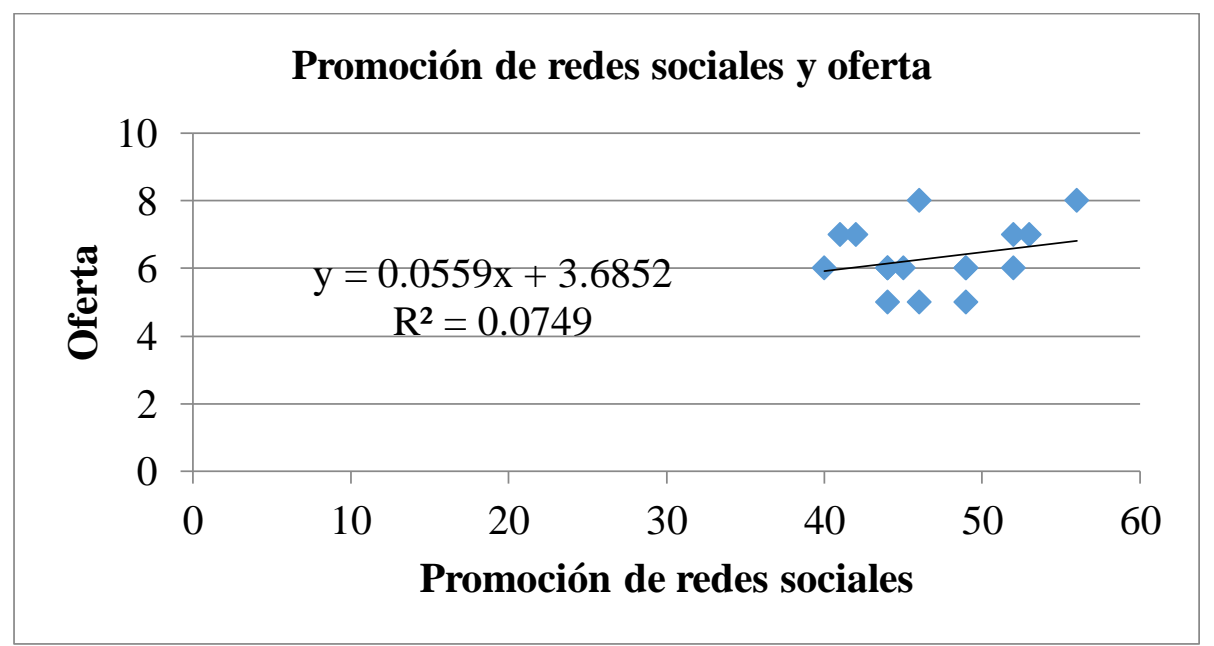

Figura 5. Relación entre la oferta y promoción en redes sociales, 2017. (Fuente. Elaboración propia mediante el procesador SPSS V22 a partir de los datos recogidos mediante los instrumentos).

En función con el segundo objetivo específico; se determinó que el grado de correlación entre la promoción en redes sociales con la demanda inherente a la participación en el mercado es 0,282; es decir, se obtuvo un grado de correlación baja y con dirección positiva, lo cual significa que la promoción en redes sociales inciden directamente en la 
cantidad de ventas y apertura a nuevos clientes. Sin embargo, la correlación es poco significativa; porque el examen estadístico bilateral y de acuerdo a la regla de decisión, frente a un p-valor $(0.145 \geq 0.05)$ se acepta la hipótesis alterna y se concluye que existe una relación directa y poco significativa entre la promoción en redes sociales con la oferta inherente a la participación en el mercado; tal como se aprecia en la tabla 5 y figura 6 respectivamente.

Igualmente, el coeficiente de determinación indica que la promoción en redes sociales con la demanda inherente a la participación en el mercado es explicada por el $0.79 \%$ respecto a la promoción en redes sociales y la diferencia se infiere que se debe a otros factores o causas ajenas a la variable mencionada. Por tanto, se puede asumir que hay una correlación lineal poco significativa entre ambas variables de estudio.

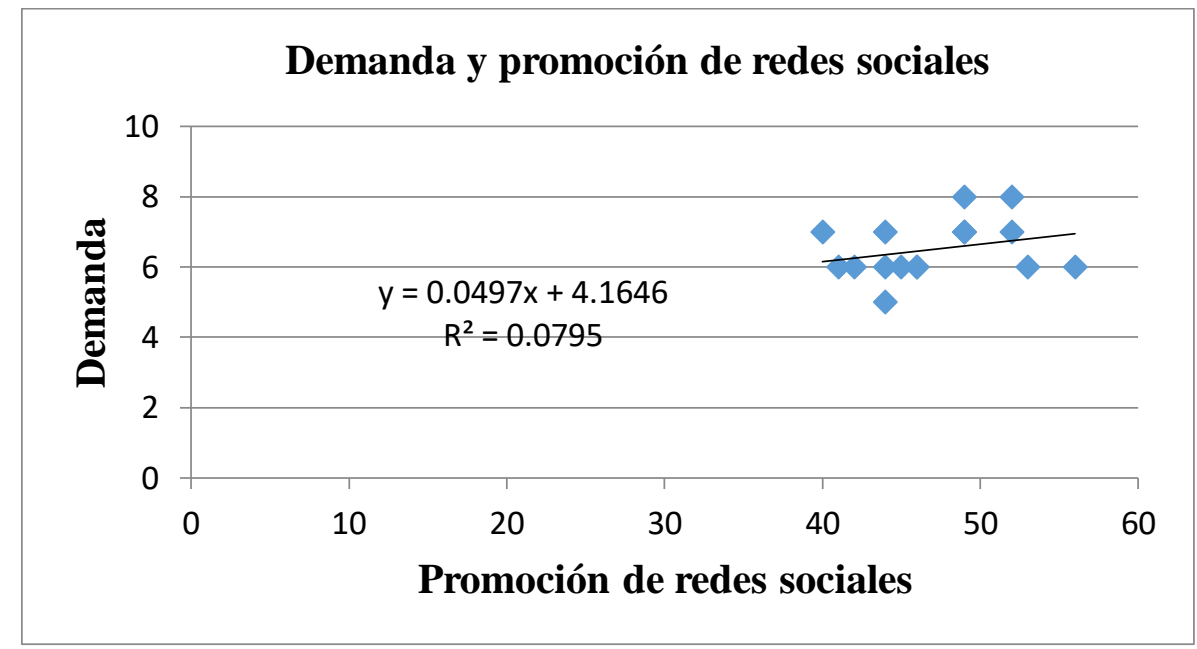

Figura 6. Relación entre la demanda y promoción en redes sociales, 2017. (Fuente. Elaboración propia mediante el procesador SPSS V22 a partir de los datos recogidos mediante los instrumentos).

Respecto al tercer objetivo específico; se determinó que el grado de correlación entre la promoción en redes sociales con la competencia inherente a la participación en el mercado es 0,489; es decir, se obtuvo un grado de correlación muy baja y con dirección positiva, lo cual significa que la promoción en redes sociales inciden directamente con las empresas competidoras y los precios del mercado. Sin embargo, la correlación es significativa; porque el examen estadístico bilateral y de acuerdo a la regla de decisión, frente a un pvalor $(0.027 \leq 0.05)$ se rechaza la hipótesis nula y se concluye que existe una relación directa y significativa entre la promoción en redes sociales con competencia inherente a la participación en el mercado; tal como se aprecia en la tabla 5 y figura 7 respectivamente. 
Igualmente, el coeficiente de determinación indica que la promoción en redes sociales con competencia inherente a la participación en el mercado es explicada por el $1.73 \%$ respecto a la promoción en redes sociales y la diferencia se infiere que se debe a otros factores o causas ajenas a la variable mencionada. Por tanto, se puede asumir que hay una correlación lineal y significativa entre ambas variables de estudio.

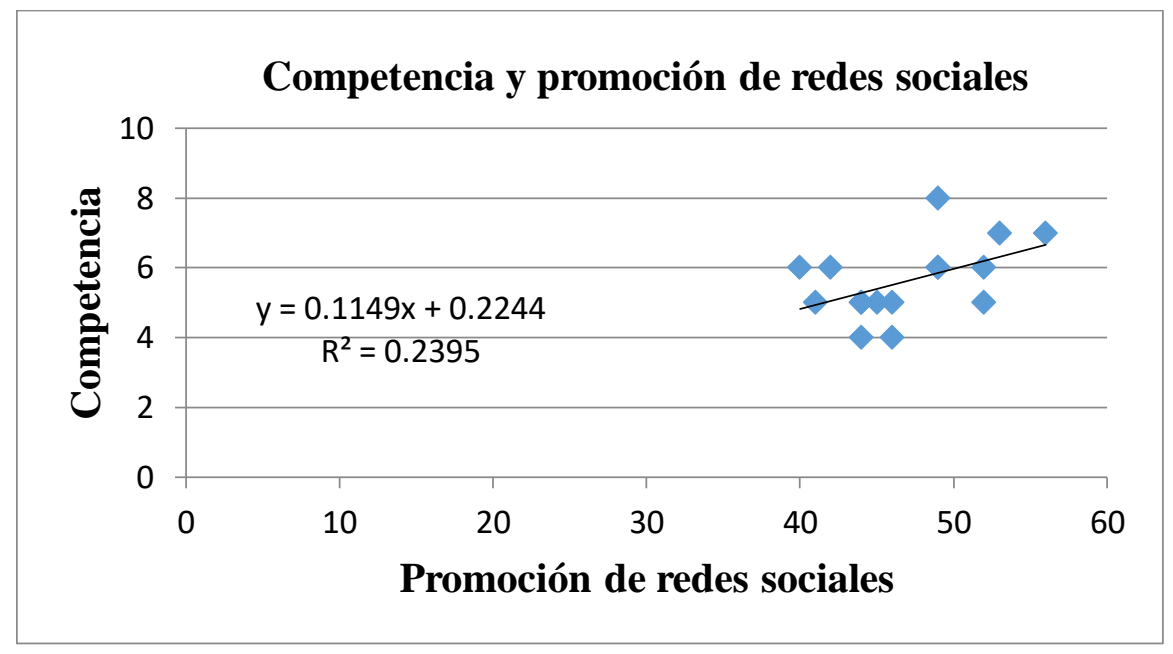

Figura 7. Relación entre la competencia y promoción en redes sociales, 2017. (Fuente. Elaboración propia mediante el procesador SPSS V22 a partir de los datos recogidos mediante los instrumentos).

\subsection{Discusión de resultados}

Después de haber procesado y analizado los resultados en torno a las medidas estadísticas para cada una de las dimensiones de la promoción en redes sociales y la participación en el mercado, así como establecer la relación entre dichas variables; corresponde argumentar los resultados obtenidos con los antecedentes de la presente investigación y las principales teorías que sustentan las variables.

En el análisis a nivel descriptivo, se obtuvo un $62 \%$ de agencias que consideran que la promoción en redes sociales es media, un 25\% que lo considera como alta y un 13\% bajo, Es decir, las dimensiones de Facebook, página web y Fanpage, no están no han sido muy efectivas ni eficientes con la información y publicaciones que realizan las agencias de viajes. Con respecto a la participación en el mercado, se obtuvo que un $56 \%$ de agencias mencionan que la participación en el mercado es media y un $44 \%$ es alta. Es decir, con respecto a las dimensiones de oferta, demanda y competitividad no tienen mayores resultados debido a que falta mejorar en la cobertura de atención para cubrir las 
expectativas del cliente, mejorar su cartera de clientes mejorando sus precios en relación a su competencia.

Según Reales, Bohórquez y Rueda (1993), las redes sociales son parte de un sistema abierto, corporativo y de propósito constructivo que, mediante un intercambio dinámico, energético en materia de información, logra potenciar a las empresas que lo utilizan (Citado en Carrión, 2015 p. 51). Actualmente, las más utilizadas por las empresas son: El facebook, páginas web y Fanpage, entre otras. Con respecto a la participación en el mercado, es el porcentaje que una empresa tiene del mercado, expresado en unidades del mismo tipo o el volumen de ventas explicado en valores monetarios de un producto o servicio específico.

Se puede medir a través de la oferta, demanda y competencia (Palomino, 2016). En sí, las empresas deben saber usar la información adecuada en redes sociales para poder aprovecharlas de una mejor manera, incluso, trabajar fuertemente en la variable participación en el mercado a través de indicadores de las dimensiones como la cobertura en la atención para poder ampliar la cartera de clientes con mejores precios en función a la competencia de participación en el mercado para y tener una buena participación en el mercado a través de sus dimensiones y en el caso de los resultados presentados no están siendo muy efectivos para las agencias de viajes.

El análisis correlacional, indica que el grado de correlación entre la promoción en redes sociales y participación en el mercado, es de $\mathbf{0 , 5 7 1}$; es decir, se obtuvo un grado de correlación muy baja y con dirección positiva, lo cual significa que la promoción en redes sociales de las agencias de viajes asociadas a APAVIT San Martín, con sus dimensiones de Facebook, página web y Fanpage, inciden directamente en la participación en el mercado y en sus dimensiones de oferta, demanda y competencia de las agencias de viajes. Además, la correlación fue significativa en el nivel 0,010 con un examen estadístico bilateral; es decir, existe una relación directa y significativa entre la promoción en redes sociales y la participación en el mercado de las agencias de viajes asociadas a APAVIT San Martín, 2017.

En éste marco, Carrión, en su trabajo de investigación de tesis titulada, "Redes sociales y la promoción de hoteles en el distrito de Andahuaylas, 2015", llevada a cabo en la Universidad Nacional José María Arguedas Andahuaylas, concluye que existe una correlación positiva entre dichas variables. El uso de Facebook, Twitter y otras redes 
sociales, cumple una buena función en la promoción de hoteles ya que es de vital importancia para poder llegar a los clientes con una relación directa; incluso, ampliando la cobertura de los servicios que ofrecen en otros lugares. Sin embargo, en los resultados obtenidos en la presente investigación se tuvo una correlación baja y con dirección positiva; es decir, no siempre se obtiene una correlación alta con respecto a la promoción en redes sociales y participación en el mercado y sus respectivas dimensiones, tal como se aprecia en los resultados. Esto se debe a que falta fortalecer los indicadores de las dimensiones de ambas variables y dependen de otros factores.

Incluso, Palomino, en su trabajo de investigación de tesis titulada "Estrategias de marketing y la participación de mercado de la línea de toallas higiénicas Nosotras de la empresa DISGOM E.I.R.L en la ciudad de Huánuco-2015", llevada a cabo en la Universidad de Huánuco, concluye que, las estrategias de marketing sí influyen en la participación mercado de la línea de toallas higiénicas Nosotras de la empresa DISGOM E.I.R.L. Se evidencia la importancia de la aplicación de las estrategias para incrementar las ventas y así lograr mayor participación en el mercado, y en el segundo se determina la participación del mercado ligada a la alta rotación del producto.

También se determinó que la promoción es también un factor importantísimo a considerar en las empresas, a mayor uso del merchandising y herramientas promocionales que permiten un mayor incremento en las ventas, lo cual es beneficioso ya que incrementa su participación en el mercado. Además, es importante el abastecimiento de los servicios ofrecidos y la cobertura de éstos para que el cliente tenga a su alcance los servicios a la hora que necesite en forma eficiente.

De la misma forma, Malpica en su trabajo de investigación de tesis titulada "Grado de eficacia de la estrategia de personalización de marketing digital de la empresa Pinkberry Perú en la red social Instagram, Trujillo 2016”, llevada a cabo en la Universidad Privada Antenor Orrego, Trujillo, concluye que las estrategias que aplica Pinkberry a través del de las redes sociales son positivas debido a su nivel de interactividad en la obtención de respuestas por parte de los usuarios. Por otro lado, el grado de interactividad de los usuarios con lo que presentan la organización tiene un gran crecimiento lo que determina a la audiencia a lograr un alto grado de participación. Quiere decir que la promoción en redes sociales de acorde al tipo de bien o servicio que ofrezca la empresa y de acuerdo al público objetivo mejora visiblemente la demanda de los servicios. Sin embargo, es necesario escuchar a los clientes para innovar los servicios que se ofrecen y ampliar la 
cartera existente, de esa manera mejorar la competitividad y la participación en el mercado de las empresas.

Sin embargo, Solórzano y Valle, en su trabajo de investigación de tesis titulada "Estrategias de marketing para mejorar la participación de mercado de la empresa NIVISA en la ciudad de Guayaquil año 2016", llevada a cabo en la Universidad Laica Vicente Rocafuerte de Guayaquil, Ecuador, concluye que no siempre las redes sociales son elementos clave de promoción de los servicios que ofrece una empresa ya que depende de la realidad de cada lugar donde se encuentre la empresa.

Estas funcionan sólo donde los clientes estén familiarizados con la tecnología y redes sociales, para ello se deben adoptar otras medidas promocionales para tener una mayor participación en el mercado de las empresas. Además, menciona la importancia de innovación de los servicios que ofrece la empresa y emplear medios publicitarios accesibles a ellos, con mayores variedades y buena calidad en los servicios ofertados. Es decir, las estrategias de promoción deben ser efectivas, de acuerdo a cada realidad para incrementar la participación en el mercado de las empresas.

Por su parte, Alcívar y Cantos, en su trabajo de investigación de tesis titulada "Plan estratégico de Márketing para el incremento de la participación en el mercado de la empresa BRITO - S.A. de la ciudad de Guayaquil", llevada a cabo en la Universidad Politécnica Salesiana, Ecuador, concluye que, con un buen plan de marketing implementado a través de redes sociales con reuniones periódicas y seguimiento del mismo, se logró el incremento del 3\% de la participación en el mercado y mantenerse en el mismo. Con el mejoramiento de la oferta de servicios que ofrece una empresa en cuanto a la mejora de la calidad y ampliación de la cobertura del servicio, va a permitir tener mejor demanda del mismo; así mismo, mejorará la competitividad en cuanto a una incrementar su cartera de clientes e incrementar sus ventas en relación a otras empresas. Además, concluye que es importante escuchar al cliente para mejorar los servicios ofrecido y tener una mayor fidelización de los mismos, permitiendo a la empresa permanecer en el mercado por muchos años.

En efecto, la promoción en redes sociales es una herramienta fundamental e indispensable para que éstas tengan una mayor participación en el mercado mediante la oferta, demanda y competitividad. Asimismo, la Asociación Española de la Economía (AEP), dio a conocer que el $85 \%$ de compañías determinan el uso de las redes sociales con fines de 
negocio, lo que inducen a través de ello incrementan el nivel de promoción en cuanto a los productos y servicios que esta brinda a sus clientes (Revista RRHH Digital, 2017). Sin embargo, éstas tienen que ser manejadas de una forma eficiente para tener efectos positivos en los resultados. 


\section{CONCLUSIONES}

1. La promoción en redes sociales se relaciona directa y significativamente con la participación en el mercado de las agencias de viajes y Turismo San Martín APAVIT, 2017, por cuanto, se obtuvo un grado de correlación muy baja y con dirección positiva de 0,571 , es decir, la promoción en redes sociales incide directamente en las dimensiones de oferta, demanda y la competitividad inherente a la participación en el mercado.

2. La promoción en redes sociales se relaciona directa y significativamente con la oferta inherente a la participación en el mercado de las agencias de viajes y Turismo San Martín - APAVIT, 2017; pues, se obtuvo un grado de correlación baja y con dirección positiva de 0,274; es decir, que la promoción en redes sociales inciden directamente en la capacidad de abastecimiento en servicios y la capacidad de cobertura en la atención inherente a la participación en el mercado.

3. La promoción en redes sociales se relaciona directa y significativamente con la demanda inherente a la participación en el mercado de las agencias de viajes y Turismo San Martín - APAVIT, 2017; pues, se obtuvo un grado de correlación baja y con dirección positiva de 0,282; es decir, que la promoción en redes sociales inciden directamente en la cantidad de ventas y apertura a nuevos clientes inherente a la participación en el mercado.

4. La promoción en redes sociales se relaciona directa y significativamente con la competencia inherente a la participación en el mercado de las agencias de viajes y Turismo San Martín - APAVIT, 2017; pues, se obtuvo un grado de correlación mиy baja y con dirección positiva de 0,489; es decir, que la promoción en redes sociales inciden directamente con las empresas competidoras y los precios del mercado inherente a la participación en el mercado. 


\section{RECOMENDACIONES}

1. A los directivos de las agencias de viajes asociadas a APAVIT San Martín, se sugiere potenciar la implementación adecuada de políticas internas que generen mejoramiento en la promoción en redes sociales y participación en el mercado porque existe una relación directa entre dichas variables.

2. Las políticas dirigidas por los directivos de las agencias de viajes asociadas a APAVIT San Martín, deben enfocarse en la oferta inherente a la participación en el mercado; es decir, mejorar la capacidad de abastecimiento en servicios y la capacidad de cobertura en la atención, ya que existe una relación directa con la promoción en redes sociales.

3. Las políticas dirigidas por los directivos de las agencias de viajes asociadas a APAVIT San Martín, deben mejorar la demanda inherente a la participación en el mercado; es decir, aumentar la cantidad de ventas y apertura a nuevos clientes, ya que existe una relación directa con la promoción en redes sociales.

4. Las políticas dirigidas por los directivos de las agencias de viajes asociadas a APAVIT San Martín, deben orientarse a innovar en la competencia inherente a la participación en el mercado; es decir, desarrollar nuevas estrategias de mercado, con respecto a las empresas competidoras y los precios del mercado, ya que existe una relación directa con la promoción en redes sociales. 


\section{REFERENCIAS BIBLIOGRÁFICAS}

\section{Físicos}

Hernández R. Fernández y otros (2014). Metodología de la investigación. Ciudad de México, Ed. (6). Ed. Mc Graw - Will.

Asociación Peruana de Agencias de Viajes en la Región San Martín- APAVIT, (2017).

\section{Web}

Alcaide, J. A., Díaz, E. y Espinoza, R. (2013). Marketing y Pymes: Principales claves de marketing en la pequeña y mediana empresa, (Primera ed.). Madrid, España: www.marketingypymesebook.com. Recuperado el 06 de 03 de 2017, de http://www.marketingypymesebook.com/wp content/uploads/2013/04/MARKETING-Y-PYMES.pdf

Alcívar, A., y Cantos M. (2014). Plan estratégico de Márketing para el incremento de la participación en el mercado de la empresa BRITO - S.A. de la ciudad de Guayaquil”. (Tesis de pre grado). Universidad Politécnica Salesiana, Ecuador. Recuperado de: https://dspace.ups.edu.ec/bitstream/123456789/7276/1/UPSGT000700.pdf.

Cárdenas, C. (2013). Influencia de las redes sociales en el rendimiento académico de los alumnos del $5^{\circ}$ grado del nivel secundario de la I.E. aplicación $N^{\circ} 0006$ en la provincia de mariscal Cáceres - Juanjui. (Tesis de pre grado). Universidad Nacional de San Martin, Tarapoto. Recuperado de: http://repositorio.unsm.edu.pe/bitstream/handle/11458/1105/ITEM\%40114581015.pdf?sequence $=1 \&$ is Allowed $=\mathrm{y}$

Cámara Nacional del Turismo en el Perú - CANATUR, (2017). Perú recibe solo el 0.3\% del turismo mundial y el 11\% de llegadas a Sudamérica. Blog virtual. Recuperado de: http://www.portaldeturismo.pe/noticia/peru-recibe-el-0-3-del-turismomundial-y-el-11-de-llegadas-a-sudamerica 
Carrión N, (2015). Redes sociales y la promoción de hoteles en el distrito de Andahuaylas, 2015. Tesis de pre grado. Universidad Nacional José María Arguedas. Andahuaylas, Perú. Recuperado de: http://repositorio.unajma.edu.pe/bitstream/handle/123456789/243/Nancy_Carri \%C3\%B3n_Tesis_Titulo_2016.pdf?sequence=1\&isAllowed=y.

Chong, J. L., Aizpuru, M., y Cárdenas, A. (2007) Promoción de ventas: herramienta básicas del marketing integral. Buenos Aires, Argentina: Ediciones Granica. Recuperado el 02 de 03 de 2017, https://ebookcentral.proquest.com/lib/elibroindividuales/detail.action?docID=32 25160\&query=PROMOCI\%C3\%93N\%20DE\%20REDES\%20SOCIALES\%20

Ferrell, O. y. (2012). Estrategia de Marketing (Quinta ed.). México, México: Cengage Learning Editores, S.A. de C.V., Compañía de Cengage Learning, Inc. Recuperado el 23 de 02 de 2017, de: http://s2d8a19afa3ca3e76.jimcontent.com/download/version/1446511996/modul e/10905856877/name/Libros_Estrategia\%20de\%20Marketing_OCFerrell.pdf.

Grandi, C. (2013). "El uso de las redes sociales como estrategia de marketing en empresas del sector hotelero: una revisión del estado del arte. (Tesis de pregrado). Universidad Politécnica de Valencia. Recuperado de: https://riunet.upv.es/bitstream/handle/10251/34723/TFM\%20CLAUDIA\%20GR ANDI\%20BUSTILLOS.pdf?sequence=1

Gómez, C. (2016). Uso de las redes sociales de internet para mejorar la participación política de la juventud popular cristiana de lima metropolitana. (Tesis de pre grado). Universidad Nacional de San Martin, Tarapoto. Recuperado de: http://repositorio.unsm.edu.pe/bitstream/handle/11458/1116/ITEM\%40114581016.pdf? sequence $=1$ \&is Allowed $=y$

Ibañez, M. (2014). Redes sociales para PYMES: Introducción al Community. (M. Forgueira, Ed.) España, Ministerio de Educación de España . Recuperado el 06 de 03

de 2017 , de: 
https://ebookcentral.proquest.com/lib/elibroindividuales/detail.action?docID=32 24484\&query=PROMOCI\%C3\%93N\%20DE\%20REDES\%20SOCIALES\%20

Kotler, P. y Keller, K. (2012). Dirección de marketing. Catorceava edición. México: Editorial Pearson Educación. Recuperado el 06 de 03 de 2017, de: https://asesoresenturismoperu.files.wordpress.com/2016/05/182-direccion-demarketing-philip-kotler.pdf

Málave, N. (2007) Trabajo modelo para enfoques de investigación acción participativa programas nacionales de formación. Escala tipo Likert. UPTPARÍA. Maturín. Recuperado de: http://uptparia.edu.ve/documentos/F\%C3\%ADsico\%20de\%20Escala\%20Likert. pdf.

Neira, E. (2013). El espectador Social: las redes sociales en la promoción cinematográfica (Primera ed.). Barcelona , España: Editorial UOC. Recuperado el 02 de 03 de 2017 ,

de: https://ebookcentral.proquest.com/lib/elibroindividuales/detail.action?docID=32 22229\&query=PROMOCI\%C3\%93N\%20DE\%20REDES\%20SOCIALES\%20\#

Observatorio Regional de IA Sociedad de la Información de Castilla y León (ORSI, 2012). Guía Práctica de Marketing Digital para Pymes. Editorial, Cámaras de Comercio e Industria de Castilla y León. Marketing. digital para Pymes. España, Cámaras Castilla y León . Recuperado el 06 de 03 de 2017, de: http://bibliotecadigital.jcyl.es/i18n/catalogo_imagenes/grupo.cmd?path=100600 82

Organización Mundial del Turismo - OMT, (13 de Junio, 2017). Panorama OMT del turismo internacional. Revista virtual, UNWTO, ISBN: 181.176.81.212. Recuperado de: https://www.e-unwto.org/doi/pdf/10.18111/9789284419043

Peñaranda C., (2017). Informe económico del turismo. Informe virtual, La cámara. Recuperado de: 
https://www.camaralima.org.pe/repositorioaps/0/0/par/r820_2/informe\%20econo mico.pdf

Palomino, J., (2015). Estrategias de marketing y la participación de mercado de la línea de toallas higiénicas Nosotras de la empresa DISGOM E.I.R.L en la ciudad de Hиánисо-2015”. (Tesis de pre grado). Universidad de Huánuco, Perú. Recuperado de: http://repositorio.udh.edu.pe/bitstream/handle/123456789/102/jose_tesis_titulo_ 2015.pdf.pdf?sequence $=1 \&$ is Allowed $=\mathrm{y}$

RR.HH. DIGITAL, (2017). El 85\% de las empresas españolas usa las redes sociales con fines de negocio. Periódico virtual. Recuperado de: http://www.rrhhdigital.com/secciones/tecnologia-e-innovacion/128142/El-85de-las-empresas-espanolas-usa-las-redes-sociales-con-fines-de-negocio.

Sanagustín, E. (2017). Plan de contenidos para medios sociales (Primera ed.). Barcelona, España: Editorial UOC. Recuperado el 02 de 03 de 2017, de: https://ebookcentral.proquest.com/lib/elibroindividuales/reader.action?docID=52 14315\&query=PROMOCI\%C3\%93N+DE+REDES+SOCIALES

Solórzano, G. y Valle, A. (2016). Estrategias de marketing para mejorar la participación de mercado de la empresa UNIVISA en la ciudad de Guayaquil año 2016. (Tesis de pre grado). Universidad Laica Vicente Rocafuerte de Guayaquil, Ecuador. Recuperado de: http://www.eumed.net/cursecon/ecolat/ec/2017/univisa.html.

Valls, M. (2016). Las Redes Sociales: herramienta de gestión empresarial. Buenos Aires , Argentina : UGERMAN EDITO, Ciencia y Técnica. Recuperado el 03 de 03 de 2017

de: https://ebookcentral.proquest.com/lib/elibroindividuales/reader.action?docID=45 36704\&query=PROMOCI\%C3\%93N+DE+REDES+SOCIALES 
ANEXOS 


\section{Anexo 1: Matriz de consistencia}

Título: Promoción en Redes Sociales y Participación en el Mercado de la Asociación Peruana de Agencias de Viajes y Turismo San Martín - APAVIT, en el distrito de Tarapoto, 2017.

\begin{tabular}{|c|c|c|c|c|c|}
\hline & & & & & Br: Aching M., y Torres G. \\
\hline & & & & & \\
\hline Problema & Objetivos & Hipótesis & & & ariables de estudio \\
\hline Problema general & Objetivo general & Hipótesis general & & Variable 1 & Promoción en redes sociales \\
\hline $\begin{array}{l}\text { ¿Cómo se relaciona la } \\
\text { promoción en redes sociales } \\
\text { y la participación en el } \\
\text { mercado de la Asociación } \\
\text { Peruana de Agencias de } \\
\text { Viajes y Turismo San Martín } \\
\text { - APAVIT, en el distrito de }\end{array}$ & $\begin{array}{l}\text { Determinar el grado de } \\
\text { relación entre } \\
\text { promoción en redes sociales } \\
\text { y la participación en el } \\
\text { mercado de la Asociación } \\
\text { Peruana de Agencias de } \\
\text { Viajes y Turismo San Martín }\end{array}$ & $\begin{array}{l}\text { La promoción en redes sociales } \\
\text { se relaciona significativamente } \\
\text { con la participación en el } \\
\text { mercado de la Asociación } \\
\text { Peruana de Agencias de Viajes y } \\
\text { Turismo San Martín - APAVIT, } \\
\text { en el distrito de Tarapoto, } 2017 \text {. }\end{array}$ & $\begin{array}{l}\text { Definición ce } \\
\text { conceptualizan } \\
\text { mediante un i } \\
\text { integrantes log } \\
\text { Definición of } \\
\text { Facebook, P }\end{array}$ & $\begin{array}{l}\text { ceptual. Según } \\
\text { s a un sistema hu } \\
\text { ercambio dinám } \\
\text { la potenciación c } \\
\text { racional: Son } \\
\text { ina Web, Fan }\end{array}$ & $\begin{array}{l}\text { Reales, Bohórquez y Rueda (1993), es la forma en que } \\
\text { lano abierto, cooperativo y de propósito constructivo que } \\
\text { o, ya sea de energía, materia e información de sus } \\
\text { sus recursos (Citado en Carrión, } 2015 \text { p. 51). } \\
\text { quellas redes más utilizadas en el medio como } \\
\text { age. }\end{array}$ \\
\hline 1 arapoto, $201 /$ ! & $\begin{array}{l}\text { - APAVIT, en el distrito de } \\
\text { Tarapoto, } 2017 .\end{array}$ & & Varia & Dimensiones & Indicadores \\
\hline Problemas específicos & Objetivos específicos & Hipótesis específicas & & & \\
\hline $\begin{array}{l}\text { ¿Cómo se relaciona la } \\
\text { promoción en redes sociales } \\
\text { con la oferta inherente a la }\end{array}$ & $\begin{array}{l}\text { Conocer el grado de relación } \\
\text { entre la promoción en redes } \\
\text { sociales con la oferta }\end{array}$ & $\begin{array}{l}\text { La promoción en redes sociales } \\
\text { se relaciona significativamente } \\
\text { con la oferta inherente a la }\end{array}$ & $\frac{\tilde{\omega}}{\frac{\pi}{0}}$ & Facebook & $\begin{array}{ll}\text { - } & \text { Publicaciones } \\
\text { - } & \text { Comentarios } \\
\text { - } & \text { Contactos } \\
\end{array}$ \\
\hline $\begin{array}{l}\text { participación en el mercado } \\
\text { de la Asociación Peruana de } \\
\text { Agencias de Viajes y }\end{array}$ & $\begin{array}{l}\text { inherente a la participación } \\
\text { en el mercado de la } \\
\text { Asociación Peruana de }\end{array}$ & $\begin{array}{l}\text { participación en el mercado de } \\
\text { la Asociación Peruana de } \\
\text { Agencias de Viajes y Turismo }\end{array}$ & $\begin{array}{l}\frac{\mathscr{d}}{0} \\
\stackrel{\Xi}{0} \\
0 \\
\tilde{0}\end{array}$ & Página Web & $\begin{array}{ll}- & \text { Perfiles } \\
- & \text { Publicaciones } \\
- & \text { Comentarios } \\
- & \text { Seguidores } \\
\end{array}$ \\
\hline $\begin{array}{l}\text { Turismo San Martín - } \\
\text { APAVIT, en el distrito de } \\
\text { Tarapoto, 2017? }\end{array}$ & $\begin{array}{lccc}\text { Agencias } & \text { de } & \text { Viajes } & \text { y } \\
\text { Turismo } & \text { San } & \text { Martín } & - \\
\text { APAVIT, en el } & \text { distrito de } \\
\text { Tarapoto, 2017. }\end{array}$ & $\begin{array}{l}\text { San Martín - APAVIT, en el } \\
\text { distrito de Tarapoto, } 2017 .\end{array}$ & $\begin{array}{l}: 0 \\
0 \\
0 \\
0 \\
0 \\
0\end{array}$ & Fanpage & $\begin{array}{ll}- & \text { Perfiles } \\
\text { - } & \text { Publicaciones } \\
\text { - } & \text { Comentarios } \\
\text { - } & \text { Seguidores } \\
\end{array}$ \\
\hline $\begin{array}{l}\text { ¿Cómo se relaciona la } \\
\text { promoción en redes sociales } \\
\text { con la demanda inherente a } \\
\text { la participación en el } \\
\text { mercado de la Asociación } \\
\text { Peruana de Agencias de }\end{array}$ & $\begin{array}{l}\text { Conocer el grado de relación } \\
\text { entre la promoción en redes } \\
\text { sociales con la demanda } \\
\text { inherente a la participación } \\
\text { en el mercado de la } \\
\text { Asociación Peruana de }\end{array}$ & $\begin{array}{l}\text { La promoción en redes sociales } \\
\text { se relaciona significativamente } \\
\text { con la demanda inherente a la } \\
\text { participación en el mercado de } \\
\text { la Asociación Peruana de } \\
\text { Agencias de Viajes y Turismo }\end{array}$ & $\begin{array}{l}\text { Definición c } \\
\text { expresado en } \\
\text { monetarios de }\end{array}$ & $\begin{array}{l}\text { ición. Para medi } \\
\text { l con cinco categ } \\
\text { Variable 2: } \\
\text { iceptual. Se r } \\
\text { hidades del misr } \\
\text { i producto o servi }\end{array}$ & $\begin{array}{l}\text { la variable "Promoción en redes sociales" se empleará } \\
\text { rías y sus respectivos equivalentes cuantitativos. } \\
\text { Participación en el mercado. } \\
\text { fiere al porcentaje que una empresa tiene del mercado, } \\
\text { o tipo o el volumen de ventas explicado en valores } \\
\text { io específico (Palomino, 2016). }\end{array}$ \\
\hline
\end{tabular}

Br: Aching M., y Torres G. 


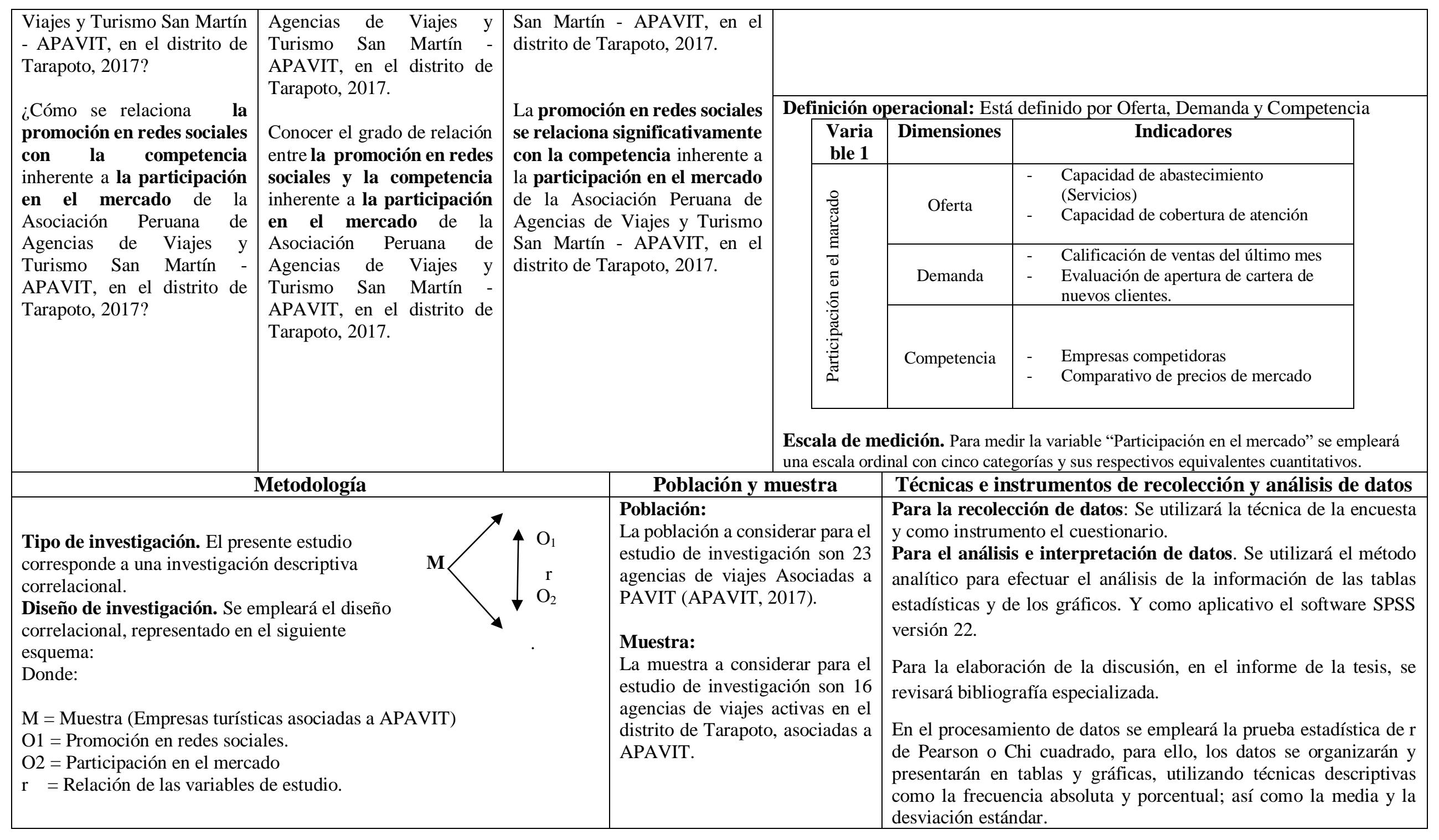



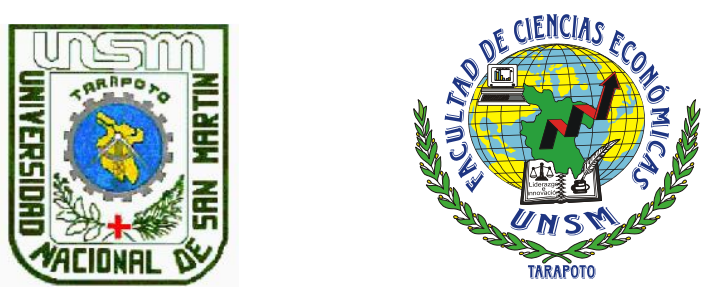

ENCUESTA DIRIGIDA A EMPRESAS TURÍSTICAS ASOCIADAS A APAVIT, PARA CONOCER LA PROMOCIÓN EN REDES SOCIALES DE LA ASOCIACIÓN PERUANA DE AGENCIAS DE VIAJES Y TURISMO SAN MARTÍN - APAVIT, EN EL DISTRITO DE TARAPOTO.

\section{Fecha:}

Instrucciones. Distinguido asociado de APAVIT, con el propósito de conocer sobre la promoción en redes sociales de la Asociación peruana de Agencias de Viajes y Turismo San Martín - APAVIT San Martín, en el distrito de Tarapoto, 2017, le solicitamos valorar cada uno de las afirmaciones. Al respecto, pueden existir distintas opiniones, por lo tanto, NO HAY RESPUESTAS CORRECTAS NI INCORRECTAS. De antemano agradecemos su colaboración con esta actividad. De acuerdo a su opinión marque con una $(\mathrm{X})$ en el casillero correspondiente según la escala de medición.

Instrucciones: Lea atentamente cada ítems y responda con una $\mathrm{X}$ en los recuadros según su propio criterio.

: Muy malo $=1 \quad$ Malo $=2 \quad$ Regular $=3 \quad$ Bueno $=4 \quad$ Muy bueno $=5$

\begin{tabular}{|c|c|c|c|c|c|}
\hline \multirow{2}{*}{ Ítem / Indicador } & \multicolumn{4}{|c|}{ Indicador } & \\
\hline & 1 & 2 & 3 & 4 & 5 \\
\hline$>$ FACEBOOK & & & & & \\
\hline $\begin{array}{l}\text { 1. Los perfiles en Facebook como elementos clave } \\
\text { en la promoción en redes sociales de su agencia } \\
\text { de viajes son considerados como: }\end{array}$ & & & & & \\
\hline $\begin{array}{l}\text { 2. Las publicaciones en redes sociales para } \\
\text { promocionar los servicios de su agencia de } \\
\text { viajes son consideradas como: }\end{array}$ & & & & & \\
\hline $\begin{array}{l}\text { 3. Los comentarios que recibe en las publicaciones } \\
\text { de los servicios que ofrece la agencia de viajes } \\
\text { por parte del público, son considerados: }\end{array}$ & & & & & \\
\hline $\begin{array}{l}\text { 4. La cantidad de amigos o contactos agregados en } \\
\text { su Facebook para la promoción de los servicios } \\
\text { que ofrece, es considerada como: }\end{array}$ & & & & & \\
\hline$>$ PÁGINA WEB & & & & & \\
\hline
\end{tabular}


5. Los perfiles presentados en la página web de la agencia, con relación a la influencia de promoción de su agencia de viajes son considerados como:

6. Las publicaciones en su página web para promocionar los productos que brinda su agencia de viajes, son considerados como:

7. Los comentarios de las publicaciones en su página web, con relación a la importancia de promoción de su agencia de viajes son considerados como:

8. La cantidad de contactos en su página web referente a determinación en la promoción de su agencia de viajes son considerados:

\section{FANPAGE}

9. Cómo evalúa la influencia del perfil en su Fanpage para promocionar su agencia de viajes.

10. Considera que las publicaciones que realiza en su Fanpage influyen en la promoción de su agencia de viajes son:

11. Los comentarios de las publicaciones en su Fanpage, con relación a la importancia de promoción de su agencia de viajes son considerados como:

12. La cantidad de contactos en su Fanpage, referente a determinación en la promoción de su agencia de viajes son considerados: 

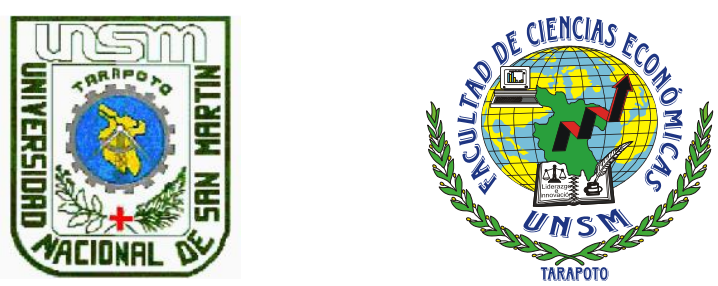

ENCUESTA DIRIGIDA A EMPRESAS TURÍSTICAS ASOCIADAS A APAVIT, PARA CONOCER LA PARTICIPACIÓN EN EL MERCADO DE LA ASOCIACIÓN PERUANA DE AGENCIAS DE VIAJES Y TURISMO SAN MARTÍN - APAVIT, EN EL DISTRITO DE TARAPOTO.

Fecha:

Instrucciones. Distinguido socio de APAVIT San Martín, con el propósito de conocer sobre la participación en el mercado de su agencia de viajes, le solicitamos valorar cada uno de las afirmaciones. Al respecto, pueden existir distintas opiniones, por lo tanto, NO HAY RESPUESTAS CORRECTAS NI INCORRECTAS. De antemano agradecemos su colaboración con esta actividad. De acuerdo a su opinión marque con una (X) en el casillero correspondiente según la escala de medición.

Escala: $\quad$ Muy malo $=1 \quad$ Malo $=2 \quad$ Regular $=3 \quad$ Bueno $=4 \quad$ Muy bueno $=5$

\begin{tabular}{|c|c|c|c|c|c|}
\hline OFERTA & 1 & 2 & 3 & 4 & 5 \\
\hline $\begin{array}{l}\text { 1. Considera que la capacidad de } \\
\text { abastecimiento (Servicios), se brinda de } \\
\text { manera: }\end{array}$ & & & & & \\
\hline $\begin{array}{l}\text { 2. Considera que la capacidad de cobertura de } \\
\text { atención es: }\end{array}$ & & & & & \\
\hline DEMANDA & 1 & 2 & 3 & 4 & 5 \\
\hline $\begin{array}{l}\text { 3. Con relación a la participación en el } \\
\text { mercado, considera las ventas del último } \\
\text { mes como: }\end{array}$ & & & & & \\
\hline $\begin{array}{l}\text { 4. Con relación a la participación en el } \\
\text { mercado, considera a la apertura de nuevos } \\
\text { clientes como: }\end{array}$ & & & & & \\
\hline COMPETENCIA & 1 & 2 & 3 & 4 & 5 \\
\hline $\begin{array}{l}\text { 5. Considera que las empresas competidoras } \\
\text { en relación a la participación en el mercado } \\
\text { son un referente... }\end{array}$ & & & & & \\
\hline $\begin{array}{l}\text { 6. Los precios que ofrece en relación al } \\
\text { mercado son: }\end{array}$ & & & & & \\
\hline
\end{tabular}

Gracias por su colaboración 
Anexo 3: Tabulación de encuestas

\begin{tabular}{|c|c|c|c|c|c|c|c|c|}
\hline \multirow{3}{*}{$\mathbf{N}^{\circ}$} & \multicolumn{6}{|c|}{ Promoción en redes sociales y Participación en el mercado } \\
\cline { 2 - 9 } & \multicolumn{3}{|c|}{ Promoción en redes sociales } & \multicolumn{3}{c|}{ Participación del mercado } \\
\cline { 2 - 9 } & $\begin{array}{c}\text { Faceboo } \\
\mathbf{k}\end{array}$ & Página web & Fanpage & Total & Oferta & $\begin{array}{c}\text { Demand } \\
\text { a }\end{array}$ & Competencia & Total \\
\hline 1 & 15 & 15 & 14 & 44 & 6 & 7 & 5 & 18 \\
\hline 2 & 19 & 18 & 16 & 53 & 7 & 6 & 7 & 20 \\
\hline 3 & 15 & 12 & 15 & 42 & 7 & 6 & 6 & 19 \\
\hline 4 & 16 & 16 & 13 & 45 & 6 & 6 & 5 & 17 \\
\hline 5 & 18 & 16 & 12 & 46 & 8 & 6 & 4 & 18 \\
\hline 6 & 17 & 13 & 14 & 44 & 5 & 5 & 5 & 15 \\
\hline 7 & 17 & 17 & 18 & 52 & 7 & 8 & 5 & 20 \\
\hline 8 & 16 & 16 & 12 & 44 & 6 & 6 & 4 & 16 \\
\hline 9 & 17 & 17 & 18 & 52 & 6 & 7 & 6 & 19 \\
\hline 10 & 16 & 12 & 18 & 46 & 5 & 6 & 5 & 16 \\
\hline 11 & 19 & 18 & 19 & 56 & 8 & 6 & 7 & 21 \\
\hline 12 & 14 & 11 & 16 & 41 & 7 & 6 & 5 & 18 \\
\hline 13 & 16 & 16 & 17 & 49 & 5 & 7 & 6 & 18 \\
\hline 14 & 14 & 16 & 19 & 49 & 6 & 8 & 6 & 20 \\
\hline 15 & 13 & 13 & 14 & 40 & 6 & 7 & 5 & 18 \\
\hline 16 & 17 & 15 & 17 & 49 & 6 & 7 & 8 & 21 \\
\hline
\end{tabular}

Fuente: Elaboración propia Aching M., y Torres G. (2018). 
Anexo 4: Confiabilidad de la promoción en redes sociales aplicada en la ciudad de Moyobamba a los socios del gremio AVITUR Alto Mayo.

\begin{tabular}{|c|c|c|c|c|c|c|c|c|c|c|}
\hline $\mathbf{N}^{\circ}$ & PREGUNTAS & SOCIO 1 & SOCIO 2 & SOCIO 3 & SOCIO 4 & SOCIO 5 & SOCIO 6 & SOCIO 7 & SOCIO 8 & $\begin{array}{l}\text { VARIANZA } \mathrm{X} \\
\text { INTEMS }\end{array}$ \\
\hline 1 & $\begin{array}{c}\text { ¿Los perfiles en Facebook como elementos } \\
\text { clave en la promoción en redes sociales de } \\
\text { su agencia de viajes son considerados } \\
\text { cómo? }\end{array}$ & 4 & 4 & 4 & 4 & 5 & 4 & 4 & 4 & 0.125 \\
\hline 2 & $\begin{array}{c}\text { ¿Las publicaciones en redes sociales para } \\
\text { promocionar los servicios de su agencia de } \\
\text { viajes son consideradas cómo? }\end{array}$ & 3 & 5 & 4 & 4 & 5 & 4 & 4 & 3 & 0.571 \\
\hline 3 & $\begin{array}{l}\text { ¿Los comentarios que recibe en las } \\
\text { publicaciones de los servicios que ofrece la } \\
\text { agencia de viajes por parte del público, son } \\
\text { considerados? }\end{array}$ & 4 & 5 & 4 & 4 & 4 & 4 & 4 & 5 & 0.214 \\
\hline 4 & $\begin{array}{c}\text { ¿La cantidad de amigos o contactos } \\
\text { agregados en su Facebook para la } \\
\text { promoción de los servicios que ofrece, es } \\
\text { considerada cómo? }\end{array}$ & 4 & 5 & 3 & 4 & 4 & 5 & 5 & 4 & 0.500 \\
\hline 5 & $\begin{array}{c}\text { ¿Los perfiles presentados en la página web } \\
\text { de la agencia, con relación a la influencia de } \\
\text { promoción de su agencia de viajes son } \\
\text { considerados cómo? }\end{array}$ & 4 & 5 & 3 & 4 & 4 & 3 & 4 & 4 & 0.411 \\
\hline 6 & $\begin{array}{l}\text { ¿Las publicaciones en su página web para } \\
\text { promocionar los productos que brinda su } \\
\text { agencia de viajes, son considerados cómo? }\end{array}$ & 4 & 5 & 3 & 4 & 4 & 4 & 4 & 4 & 0.29 \\
\hline
\end{tabular}




\begin{tabular}{|c|c|c|c|c|c|c|c|c|c|c|}
\hline 7 & $\begin{array}{l}\text { ¿Los comentarios de las publicaciones } \\
\text { en su página web, con relación a la } \\
\text { importancia de promoción de su agencia } \\
\text { de viajes son considerados cómo? }\end{array}$ & 4 & 5 & 3 & 4 & 4 & 3 & 4 & 4 & 0.41 \\
\hline 8 & $\begin{array}{l}\text { ¿La cantidad de contactos en su página } \\
\text { web referente a determinación en la } \\
\text { promoción de su agencia de viajes son } \\
\text { considerados? }\end{array}$ & 3 & 5 & 3 & 4 & 4 & 3 & 5 & 4 & 0.696 \\
\hline 9 & $\begin{array}{c}\text { ¿Cómo evalúa la influencia del perfil en } \\
\text { su Fanpage para promocionar su } \\
\text { agencia de viajes? }\end{array}$ & 4 & 5 & 4 & 4 & 4 & 3 & 5 & 3 & 0.571 \\
\hline 10 & $\begin{array}{l}\text { ¿Considera que las publicaciones que } \\
\text { realiza en su Fanpage influyen en la } \\
\text { promoción de su agencia de viajes son? }\end{array}$ & 4 & 5 & 4 & 4 & 5 & 3 & 5 & 3 & 0.70 \\
\hline 11 & $\begin{array}{l}\text { ¿Los comentarios de las publicaciones } \\
\text { en su Fanpage, con relación a la } \\
\text { importancia de promoción de su agencia } \\
\text { de viajes son considerados cómo? }\end{array}$ & 3 & 5 & 4 & 4 & 4 & 4 & 4 & 3 & 0.411 \\
\hline 12 & $\begin{array}{l}\text { ¿La cantidad de contactos en su } \\
\text { Fanpage, referente a determinación en } \\
\text { la promoción de su agencia de viajes son } \\
\text { considerados? }\end{array}$ & 3 & 5 & 3 & 4 & 4 & 4 & 4 & 3 & 0.500 \\
\hline & TOTAL & 44 & 59 & 42 & 48 & 51 & 44 & 52 & 44 & \\
\hline
\end{tabular}




\begin{tabular}{|l|c|c|}
\hline \multicolumn{1}{|c|}{ ITEMS } & VALORES & TOTAL \\
\hline MUY MALO & 1 & 0 \\
\hline MALO & 2 & 0 \\
\hline REGULAR & 3 & 20 \\
\hline BUENO & 4 & 56 \\
\hline MUY BUENO & 5 & 20 \\
\hline
\end{tabular}

\begin{tabular}{|c|r|}
\hline K & 8 \\
\hline K-1 & 7 \\
\hline suma Vi & 5.3928571 \\
\hline Vt & 32.857143 \\
\hline
\end{tabular}

\begin{tabular}{|l|r|}
\hline S1 & 1.142857143 \\
\hline & \\
\hline S2 & 0.835869565 \\
\hline & \\
\hline ABS & 0.835869565 \\
\hline
\end{tabular}

\begin{tabular}{|l|l|}
\hline CONFIABILIDAD & \\
\hline alfa & 0.955280 \\
\hline
\end{tabular}


Anexo 5: Confiabilidad de participación en el mercado aplicada en la ciudad de Moyobamba a los socios del gremio AVITUR Alto Mayo.

\begin{tabular}{|c|c|c|c|c|c|c|c|c|c|c|}
\hline $\mathbf{N}^{\circ}$ & PREGUNTAS & SOCIO 1 & SOCIO 2 & SOCIO 3 & SOCIO 4 & SOCIO 5 & SOCIO 6 & SOCIO 7 & SOCIO 8 & $\begin{array}{l}\text { VARIANZA } X \\
\text { INTEMS } \\
\end{array}$ \\
\hline 1 & $\begin{array}{l}\text { ¿Cómo considera la capacidad de } \\
\text { abastecimiento (Servicios)? }\end{array}$ & 3 & 4 & 4 & 4 & 4 & 3 & 2 & 3 & 0.553571429 \\
\hline 2 & $\begin{array}{l}\text { ¿Cómo considera la capacidad de } \\
\text { cobertura de atención? }\end{array}$ & 3 & 4 & 4 & 3 & 4 & 2 & 2 & 3 & 0.696 \\
\hline 3 & $\begin{array}{c}\text { ¿Con relación a la participación en el } \\
\text { mercado, cómo considera las ventas del } \\
\text { último mes cómo? }\end{array}$ & 2 & 4 & 4 & 3 & 4 & 2 & 3 & 3 & 0.696 \\
\hline 4 & $\begin{array}{l}\text { ¿Con relación a la participación en el } \\
\text { mercado, cómo considera a la apertura de } \\
\text { nuevos clientes cómo? }\end{array}$ & 4 & 4 & 3 & 3 & 3 & 3 & 2 & 3 & 0.411 \\
\hline 5 & $\begin{array}{l}\text { ¿Cómo considera a las empresas } \\
\text { competidoras en relación a la } \\
\text { participación en el mercado? }\end{array}$ & 2 & 3 & 4 & 2 & 3 & 3 & 2 & 2 & 0.554 \\
\hline 6 & $\begin{array}{c}\text { ¿Cómo considera a los precios que ofrece } \\
\text { en relación al mercado? }\end{array}$ & 3 & 4 & 4 & 2 & 2 & 2 & 2 & 2 & 0.84 \\
\hline & $\begin{array}{r}\text { TOTAL } \\
\end{array}$ & 17 & 23 & 23 & 17 & 20 & 15 & 13 & 16 & \\
\hline
\end{tabular}




\begin{tabular}{|l|r|r|}
\hline \multicolumn{1}{|c|}{ ITEMS } & VALORES & \multicolumn{1}{c|}{ TOTAL } \\
\hline MUY MALO & 1 & 0 \\
\hline MALO & 2 & 8 \\
\hline REGULAR & 3 & 18 \\
\hline BUENO & 4 & 15 \\
\hline MUY BUENO & 5 & 0 \\
\hline
\end{tabular}

\begin{tabular}{|r|r|}
\hline K & 8 \\
\hline$K-1$ & 7 \\
\hline suma Vi & 3.75 \\
\hline Vt & 13.42857143 \\
\hline
\end{tabular}

\begin{tabular}{|l|r|r|}
\hline S1 & 1.142857143 \\
\hline & \\
\hline S2 & 0.720744681 & \\
\hline & & \\
\hline ABS & 0.720744681 \\
\hline
\end{tabular}

Fuente: Elaboración propia Aching M., y Torres G. (2018). 


\section{Anexo 6: Galería de fotos}

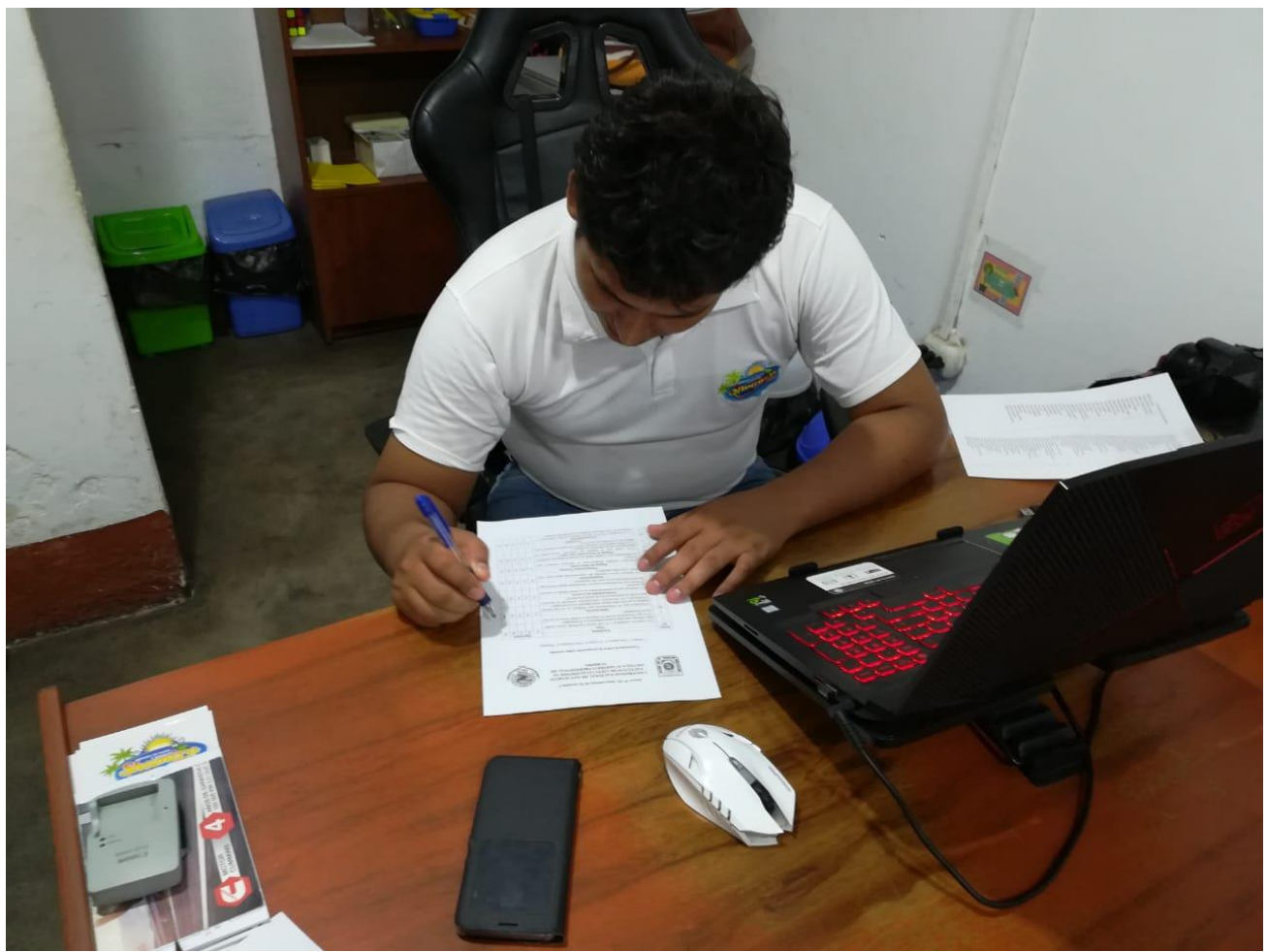

Foto 1: Socio de APAVIT San Martin - 2018

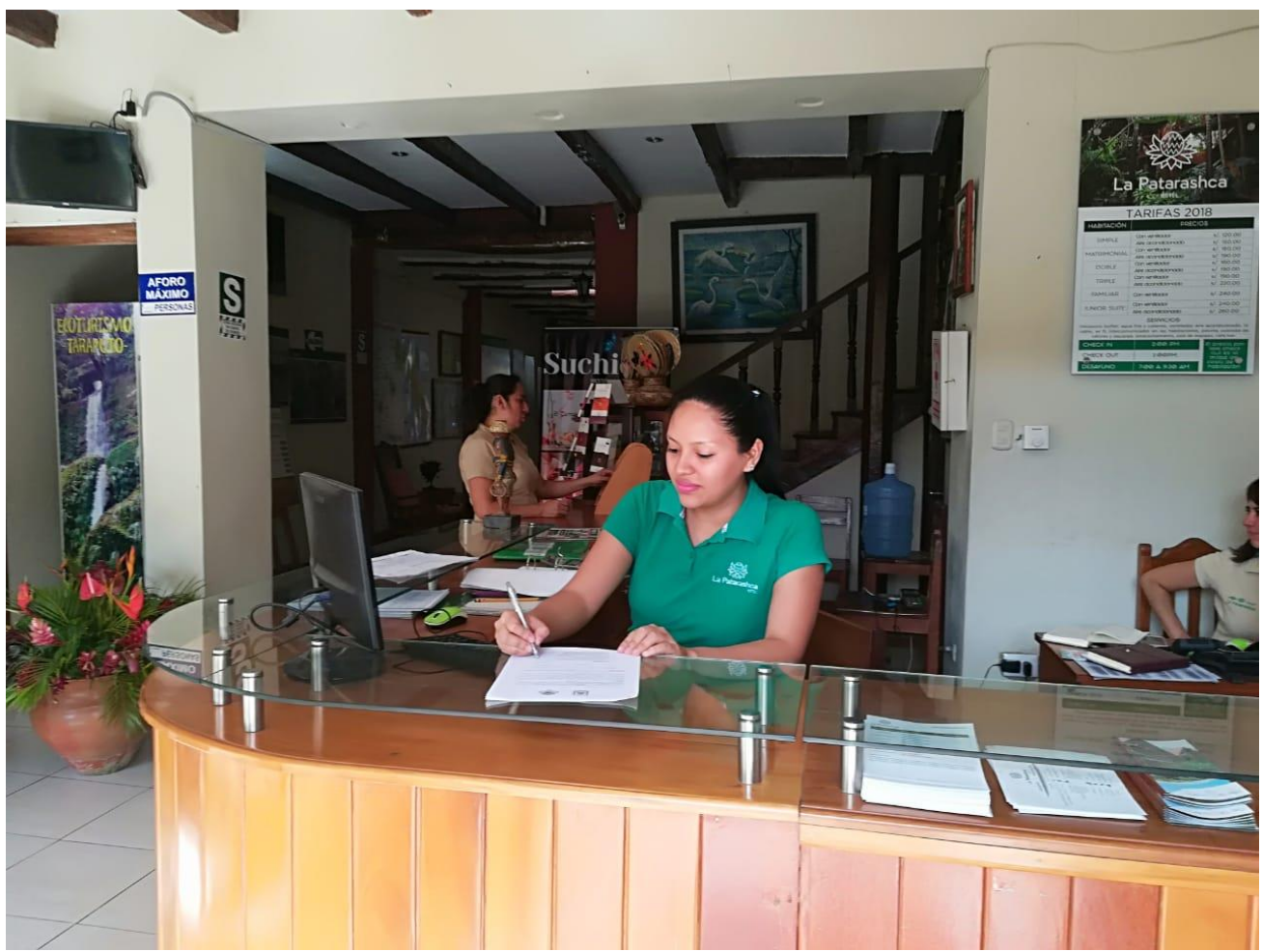

Foto 2: Socio de APAVIT San Martin - 2018. 


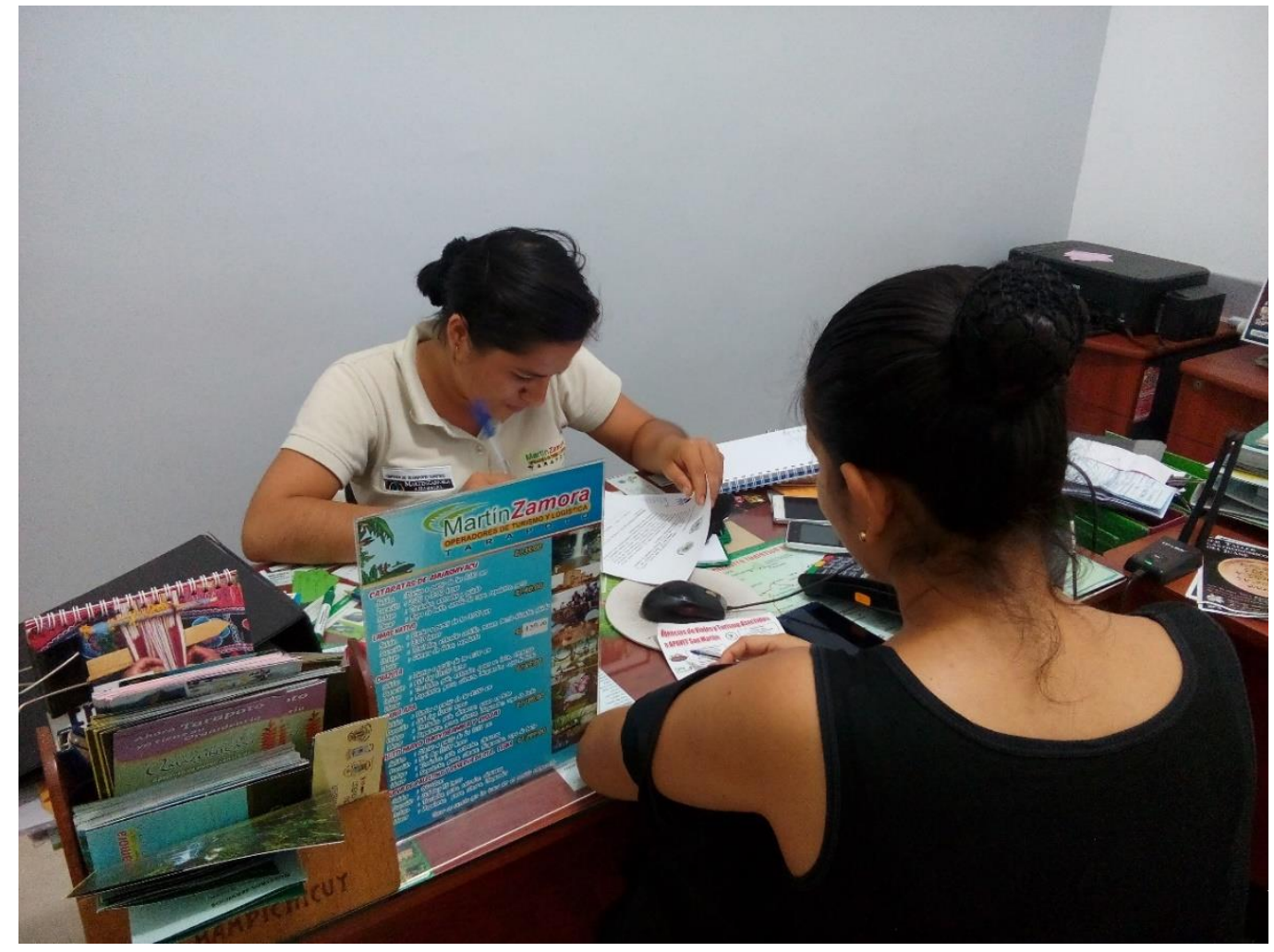

Foto 3: Encuesta agencia de viajes asociada APAVIT San Martin - 2018.

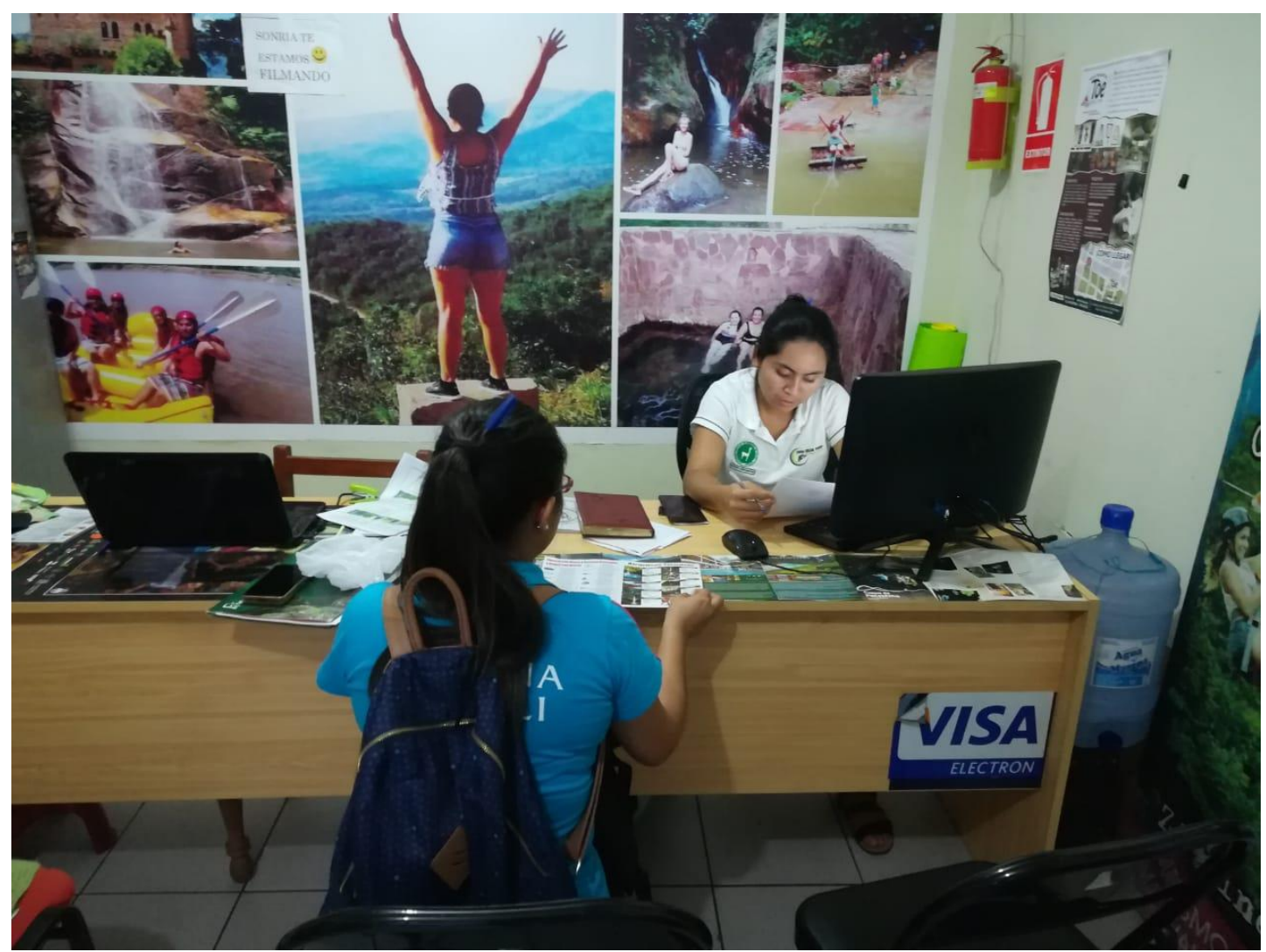

Foto 4: Socia de APAVIT San Martin llenando la encuesta - 2018. 


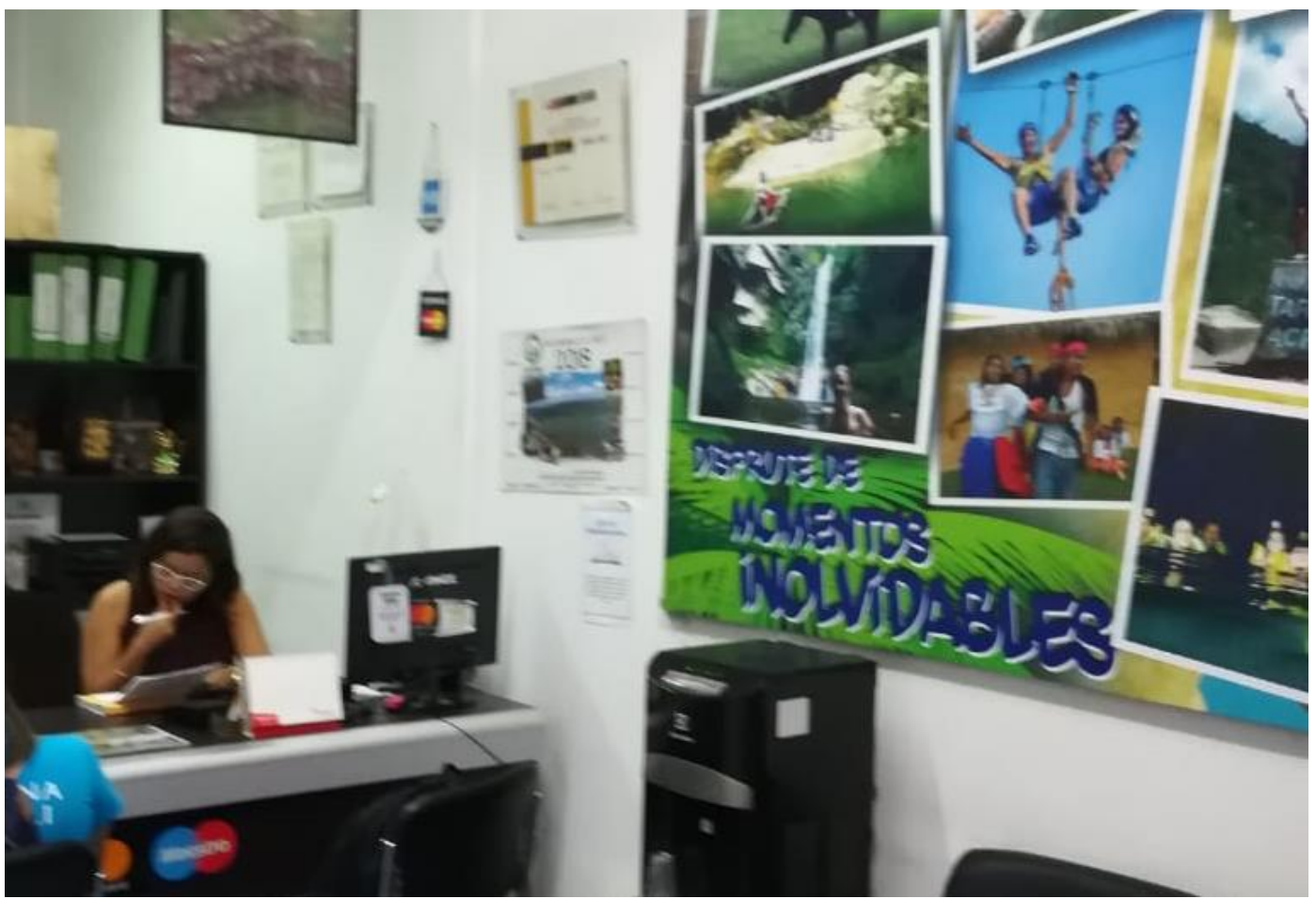

Foto 5: Socia de APAVIT San Martin respondiendo la encuesta - 2018.

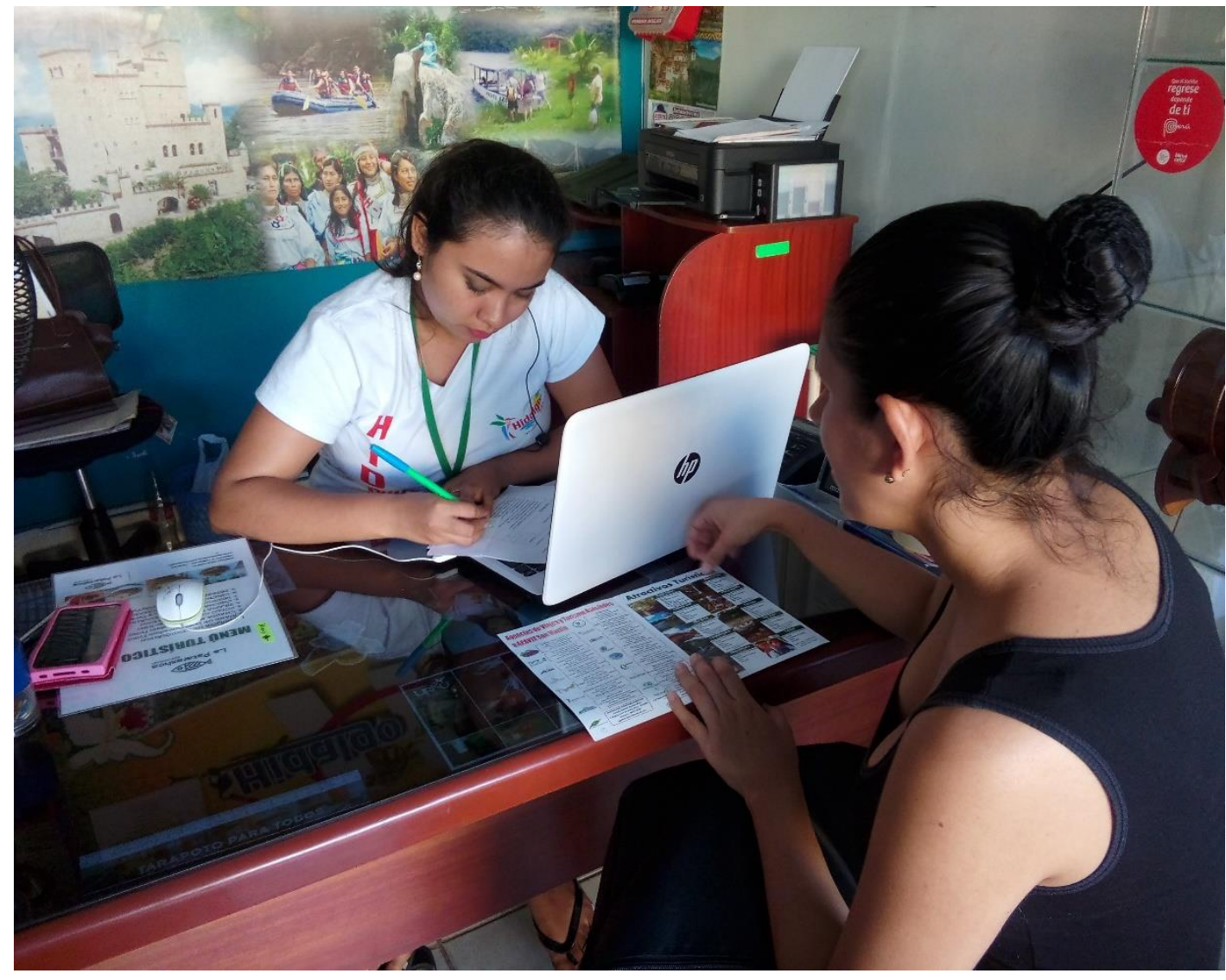

Foto 6: Desarrollando la encuesta a socia de APAVIT San Martin 2018.

Fuente: Elaboración propia Aching M., y Torres G. (2018). 